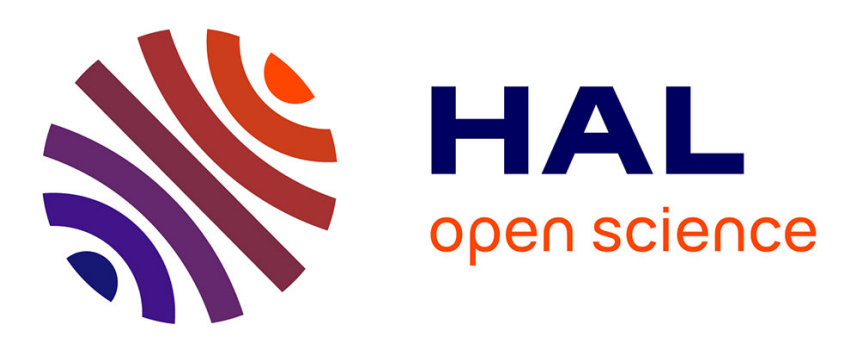

\title{
Influence of topology of LCST-based graft copolymers on responsive assembling in aqueous media
}

Hui Guo, Annie Brûlet, Pattuparambil R. Rajamohanan, Alba Marcellan, Nicolas Sanson, Dominique Hourdet

\section{- To cite this version:}

Hui Guo, Annie Brûlet, Pattuparambil R. Rajamohanan, Alba Marcellan, Nicolas Sanson, et al.. Influence of topology of LCST-based graft copolymers on responsive assembling in aqueous media. Polymer, 2015, 60, pp.164-175. 10.1016/j.polymer.2015.01.038 . hal-01114465

\section{HAL Id: hal-01114465 https: / hal.sorbonne-universite.fr/hal-01114465}

Submitted on 9 Feb 2015

HAL is a multi-disciplinary open access archive for the deposit and dissemination of scientific research documents, whether they are published or not. The documents may come from teaching and research institutions in France or abroad, or from public or private research centers.
L'archive ouverte pluridisciplinaire HAL, est destinée au dépôt et à la diffusion de documents scientifiques de niveau recherche, publiés ou non, émanant des établissements d'enseignement et de recherche français ou étrangers, des laboratoires publics ou privés. 


\section{Influence of topology of LCST-based graft}

\section{copolymers on responsive assembling in aqueous media.}

Hui Guo ${ }^{1,2}$, Annie Brûlet ${ }^{3}$, Pattuparambil R. Rajamohanan ${ }^{4}$, Alba Marcellan $^{1,2}$, Nicolas Sanson ${ }^{1,2}$ and Dominique Hourdet ${ }^{1,2} *$

${ }^{1}$ École Supérieure de Physique et de Chimie Industrielles de la Ville de Paris (ESPCI),

ParisTech, PSL Research University, Sciences et Ingénierie de la Matière Molle, CNRS UMR 7615, 10 rue Vauquelin, F-75231, Paris cedex 05, France.

${ }^{2}$ Sorbonne-Universités, UPMC Univ Paris 06, SIMM, 10 rue Vauquelin, F-75231 Paris cedex 05, France.

${ }^{3}$ Laboratoire Léon Brillouin (CNRS UMR 12), CEA Saclay, F-91191 Gif-sur-Yvette Cedex, France

${ }^{4}$ Central NMR Facility, CSIR-National Chemical Laboratory, Pune 411 008, India

* To whom correspondence should be addressed:

Tel. +33 (0)140794643 / Fax +33 (0)1 40794686

Email addresses :

hui.guo@espci.fr, brulet@1lb.saclay.cea.fr, pr.rajamohanan@ncl.res.in, alba.marcellan@espci.fr,nicolas.sanson@espci.fr,dominique.hourdet@espci.fr 


\section{ABSTRACT}

This work, based on structure/properties relationships of associating polymers, aims to investigate the role of topology in the self-assembling behavior of responsive graft copolymers. For that purpose, two graft copolymers with inverse topologies were prepared with similar amounts of water-soluble chains $(\operatorname{poly}(N, N$-dimethylacrylamide $)=$ PDMA $)$ and LCST polymer chains $($ poly $(N$-isopropylacrylamide $)=$ PNIPA $)$. In pure water, and above 3 wt $\%$, PNIPA- $g$-PDMA and PDMA- $g$-PNIPA exhibit very similar macroscopic properties with a sol/gel transition above $35{ }^{\circ} \mathrm{C}$ related to the microphase separation of PNIPA sequences. From complementary experiments, performed by DSC, ${ }^{1} \mathrm{H}$ NMR and small angle neutron scattering, we show that the phase transition of PNIPA is more abrupt when NIPA units are located within the backbone, compared to side-chains. Nevertheless, well above their transition temperature, the two copolymers display very similar bicontinuous structures where PNIPA sequences self aggregate into concentrated percolating domains (about $70 \mathrm{wt} \%$ at 60 $\left.{ }^{\circ} \mathrm{C}\right)$ characterized by a frozen dynamics. On the other hand, when salt or surfactant molecules are added into unentangled semi-dilute aqueous solution, the PNIPA-g-PDMA sample does not percolate anymore above the transition temperature while PDMA-g-PNIPA still demonstrate thermothickening properties that are correlated to the ability of water-soluble PDMA chains to bridge PNIPA aggregates.

Keywords: poly( $N$-isopropylacrylamide), thermothickening, associating polymers, graft copolymers. 


\section{INTRODUCTION}

Associating polymers have known a tremendous development during the last decades due their enhanced viscoelastic properties that find applications in a wide range of domains like food, cosmetics, paints, drilling fluids, etc [1-3]. In this framework, responsive polymers, that are able to change their macroscopic behavior under environmental conditions like ionic strength, $\mathrm{pH}$, temperature, light, red-ox activity or under external fields (electric or magnetic), are very useful for applications where enhanced properties are needed under certain conditions [4-6]. Among these various mechanisms, temperature is a common trigger that naturally occurs in many applications and thermoresponsive polymers have known a large development in different fields like oil recovery or biomedical applications [7-12]. Indeed, these systems can be efficiently used to increase or to control the viscosity of drilling fluids submitted to large temperature gradients in deep formations or to promote sol/gel transitions around body temperature with applications like injectable hydrogels and controlled drug release $[3,12-13]$.

Although cellulosic derivatives [14-15] were the first thermothickeners to be used in aqueous media, thermoresponsive systems have been widely diversified during the last two decades $[4,7,16]$. They are generally designed on the basis of block or graft architectures containing hydrophilic and water-soluble moieties alternating with responsive blocks or grafts characterized by a Lower Critical Solution Temperature (LCST) in the range of application. Quite a lot of systems, mainly based on poly( $N$-alkylacrylamide) and poly(alkylene oxide) have been reported with various level of understanding of their structure/properties relationships [17-23]. For these copolymers the key parameters are the chemical nature of both LCST and hydrophilic sequences as well as the design of associating copolymers (distribution and relative ratio between hydrophilic and "hydrophobic" moieties) that directly 
impact the level of the phase segregation (from nano- to macroscopic scale) and the final properties of aqueous formulations.

In the case of thermothickening copolymer solutions, designed with poly(ethylene oxide-copropylene oxide) derivatives, the LCST sequences self-assemble into liquid-like aggregates above their transition temperature. These hydrophobic domains behave as efficient physical cross-links and viscoelastic analysis highlight the dynamic properties of these systems with a finite lifetime of the responsive stickers [16,22]. By comparison poly( $N$-isopropylacrylamide $)$ (PNIPA) behaves rather differently as during the phase transition the PNIPA-rich phase reaches the so-called Berghmans point where it is supposed to become glassy [24-25]. Although this assumption remains controversial [26], the formation of frozen PNIPA domains above their transition temperature is often taken into account to explain the formation of stable colloidal PNIPA particles at high temperature with ineffectiveness of colloid aggregation [27] or the extraordinarily slow deswelling of macroscopic PNIPA hydrogels; the out-of equilibrium state of the gel being conserved for many days [28].

In the framework of thermothickeners with grafted architectures, the phase transition driven by LCST moieties must remain confined at a local scale to avoid the macro-phase separation and the ruin of the elastic properties. Although most of thermoresponsive graft copolymers are generally designed with a hydrophilic backbone and LCST side-chains [7,16], the inverse topology is also conceivable with similarities with weakly ionized PNIPA chains where electrostatic repulsions stabilized the transient network formed at high temperature [29]. Amazingly, a direct comparison between 3D self-assemblies of graft copolymers with similar composition but inverse topology (see Figure 1) has never been investigated so far although this comparison naturally raises a lot of questions about the structure/properties relationships. For instance we can reasonably wonder how these graft copolymers with inverse topologies 
will behave below and above the transition temperature? How the responsivity of LCST stickers (association temperature, concentration of polymer rich phase...) will be affected by the topology? What will be the microstructure of 3D self-assemblies and the corresponding viscoelastic properties? What will be the relative sensitivity of these copolymers to environmental modifications induced by adding cosolute?

In order to address the topological issue in thermoassociating graft copolymers, grafted macromolecules were prepared with similar amounts of water-soluble chains $\operatorname{poly}(N, N-$ dimethylacrylamide $)=$ PDMA $)$ and LCST polymer chains $($ poly $(N$-isopropylacrylamide $)=$ PNIPA) which exhibit a LCST around $32{ }^{\circ} \mathrm{C}$ in water. These two Yin and Yang copolymers (PNIPA-g-PDMA and PDMA-g-PNIPA), sharing identical monomers with inverse topology, are represented in Figure 1.

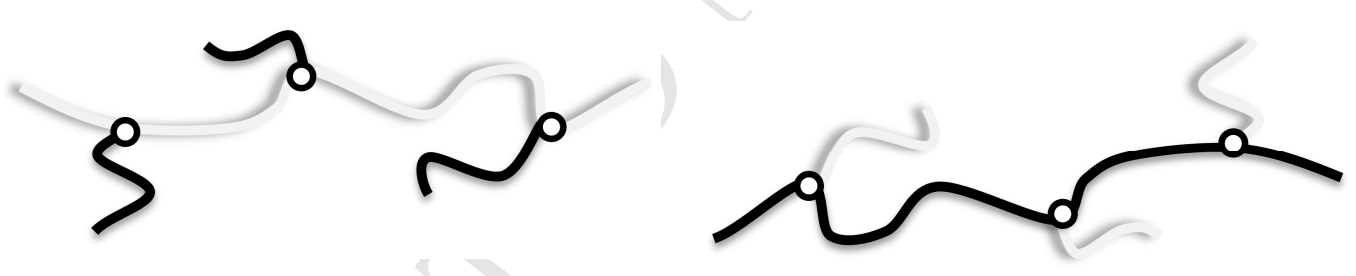

Figure 1. Schematic representation of Yin and Yang graft copolymers prepared from PDMA (-) and PNIPA (-).

Based on this set of copolymers, a detailed comparative study has been performed on semidilute solution as a function of temperature and added molecules like salt or surfactant. This original analysis, carried out by rheology, differential scanning calorimetry, NMR and light/neutron scattering techniques, surprisingly highlights very common features as well as large differences between the two copolymers that could be understood from their topology. 


\section{EXPERIMENTAL SECTION}

\section{Materials}

$\mathrm{N}$-isopropylacrylamide (NIPA, Aldrich), N,N-dimethylacrylamide (DMA, Aldrich), cysteamine hydrochloride (AET·HCl, Fluka), potassium peroxodisulfate (KPS, Aldrich), acrylic acid (AA, anhydrous > 99\%, Fluka), dicyclohexylcarbodiimide (DCCI, Aldrich), ammonium persulfate (APS, Aldrich), sodium metabisulfite (SBS, Aldrich) were used as received. All organic solvents were analytical grade and water was purified with a Millipore system combining inverse osmosis membrane (Milli RO) and ion exchange resins (Milli Q) for synthesis and purification.

\section{Synthesis of thermosensitive linear copolymers}

The synthesis of responsive linear copolymers was performed according to a three-step process. Telomers were first synthesized through free radical polymerization. Then, the macromonomers were obtained by coupling amino-terminated telomers with acrylic acid and finally graft copolymers were prepared by free radical polymerization of monomers and macromonomers. An example is given in Figure 2 in the case of PDMA-g-PNIPA and the detailed procedure is described in supporting information. In order to simplify the nomenclature of the copolymers, PNIPA- $g$-PDMA and PDMA- $g$-PNIPA will be named PN-D and PD-N, respectively. 

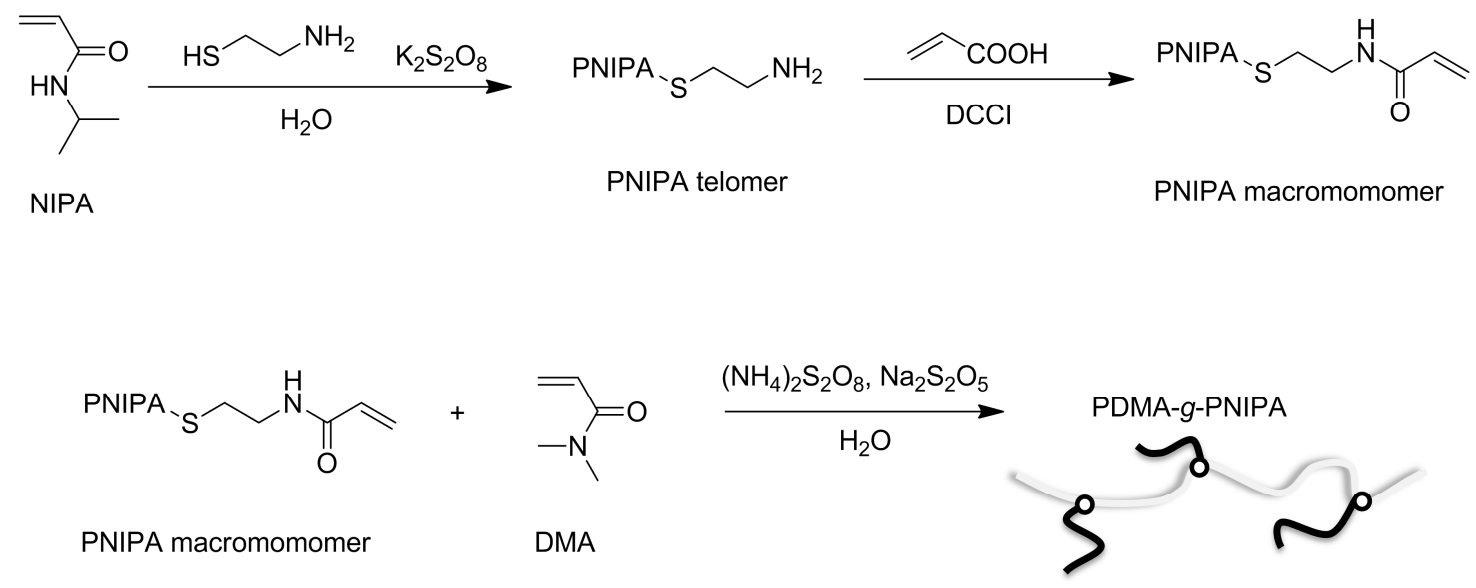

Figure 2. Three-step synthesis of graft copolymers exemplified with PDMA- $g$-PNIPA (PD-N).

\section{Size exclusion chromatography (SEC)}

Experiments were carried out with two different chromatographic systems. The first one, which was applied to the absolute characterization of polymer samples, is a Viscotek triple detector (TDA 302) equipped with three columns (OH-pak). During the analysis carried out at $28{ }^{\circ} \mathrm{C}$ the flow rate was controlled at $0.6 \mathrm{~mL} \cdot \mathrm{min}^{-1}$ using $0.2 \mathrm{M} \mathrm{NaNO}_{3}$ as mobile phase. The molar masses were derived from a universal calibration curve based on Pullulan standards from Sopares (OmniSEC software). The other chromatographic system from Waters is equipped with similar Shodex $\mathrm{OH}$-pak columns thermostated at $10{ }^{\circ} \mathrm{C}$ and a differential refractometer (Shimadzu RID-10A). This system was mainly used to follow, without purification, the conversion of the reactions. The flow rate was controlled at $0.90 \mathrm{~mL} \cdot \mathrm{min}^{-1}$ using $0.5 \mathrm{M} \mathrm{LiNO}_{3}$ as mobile phase.

\section{Nuclear magnetic resonance (NMR)}

All the NMR measurements were performed on a Bruker Avance III HD spectrometer operating at $700 \mathrm{MHz}$ for ${ }^{1} \mathrm{H}$, using a standard $5 \mathrm{~mm}$ broadband Smart probe. The temperature control was achieved by a Bruker BCU II unit and a build in temperature control unit. 
Following experimental conditions were employed for the variable temperature experiments: 32 transients, 45 degree flip angle, $2.5 \mathrm{sec}$ acquisition time, $2 \mathrm{sec}$ relaxation delay. The sample was allowed to equilibrate for $\sim 10$ minutes at each temperature. The ${ }^{1} \mathrm{H}$ chemical shifts were referred to residual HOD peak at each temperature [30]. 3wt \% solutions of PD-N and PN-D in $\mathrm{D}_{2} \mathrm{O}$ were used for the NMR measurements.

\section{Rheology}

The viscoelastic properties of the copolymers were studied in aqueous solutions, in the semidilute regime, using a stress-controlled rheometer (AR 1000 from TA Instruments) equipped with a cone/plate geometry (diameter $40 \mathrm{~mm}$, angle 2, truncature $55.9 \mu \mathrm{m}$ ). The experiments were performed in the linear viscoelastic regime which was established for each sample by a stress sweep at the lowest frequency. The temperature was controlled by a high power Peltier system that provides fast and precise adjustment of the temperature during heating and cooling stages. Typically, the experimental conditions were fixed at constant frequency $(1 \mathrm{~Hz})$ and shear stress (2 Pa). A particular care was taken to avoid the drying of the sample by using a homemade cover which prevents from water evaporation during experiment. In these conditions, dynamic moduli $\left(G^{\prime}\right.$ and $\left.G^{\prime \prime}\right)$ as well as complex viscosity $\left(\eta^{*}\right)$ were recorded between 20 and $60{ }^{\circ} \mathrm{C}$ by applying heating and cooling scans of $2{ }^{\circ} \mathrm{C} \cdot \mathrm{min}^{-1}$.

\section{Differential Scanning Calorimetry (DSC)}

The phase transition of PNIPA-based copolymers in aqueous solution was investigated by Differential Scanning Calorimetry using a DSC Q200 from TA instrument. Polymer solutions (80 mg), equilibrated with a reference filled with the same quantity of solvent, were submitted to temperature cycles between 10 and $70{ }^{\circ} \mathrm{C}$. The heating and cooling rates were similarly fixed at $2{ }^{\circ} \mathrm{C} \cdot \mathrm{min}^{-1}$. 


\section{Dynamic Light Scattering (DLS)}

Dynamic Light Scattering (DLS) was carried out on a CGS-3 goniometer system equipped with He-Ne laser illumination at $633 \mathrm{~nm}$ and an ALV/LSE-5003 correlator. All samples were initially filtered through $0.45 \mu \mathrm{m}$ Millipore syringe filters. The samples were stabilized at constant temperature for $10 \mathrm{~min}$ prior to measurement. The data were collected by monitoring the light intensity at a scattering angle of $90^{\circ}$. DLS experiments were performed on dilute solution $\left(0.1 \mathrm{~g} . \mathrm{L}^{-1}\right)$ and each measurement lasts $120 \mathrm{~s}$.

\section{Small Angle Neutron Scattering (SANS)}

SANS experiments were performed at Laboratoire Léon Brillouin (CEA-Saclay, France) on the PAXY spectrometer. The wavelength of the incident neutron beam was set at $\lambda=12 \AA$ with a corresponding sample-to-detector distance of $4.7 \mathrm{~m}$. This configuration provides a scattering vector modulus $[q=4 \pi / \lambda \sin (\theta / 2)]$ ranging between 0.002 and $0.04 \AA^{-1}$ (where $\theta$ is the scattering angle). All the samples were prepared at room temperature in $\mathrm{D}_{2} \mathrm{O}$ and transferred into 2- or 5-mm-thick quartz containers for SANS experiments. For the data treatment, the scattering from the empty quartz cell was subtracted, the efficiency of the detector cell was normalized by the intensity delivered by a pure water cell of 1 -mm thickness and absolute measurements of the scattering intensity $\mathrm{I}(\mathrm{q})\left(\mathrm{cm}^{-1}\right.$ or $\left.10^{-8} \AA^{-1}\right)$ were obtained from the direct determination of the incident neutron flux and the cell solid angle.

\section{RESULTS}

\section{Synthesis and characterization of graft copolymers}

Let us first recall that PN-D has PNIPA backbone and graft PDMA chains, while PD-N has the inverse topology with PDMA backbone and PNIPA grafts. Graft precursors and copolymers were characterized by ${ }^{1} \mathrm{H}$ NMR and SEC (Table 1). In the case of amino- 
terminated PDMA and PNIPA, the molar masses are 15 and $23 \mathrm{~kg} / \mathrm{mol}$, respectively, in good agreement with similar telomerizations performed with NIPA, DMA and other hydrophilic comonomers [31-32].

\begin{tabular}{|c|c|c|c|c|}
\hline \multirow[b]{3}{*}{ copolymers } & \multicolumn{3}{|c|}{ Table 1 Structural characterization of linear copolymers } & 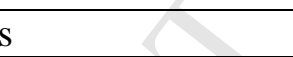 \\
\hline & \multicolumn{2}{|c|}{ Molar mass and dispersity index } & \multirow{2}{*}{$\begin{array}{c}\text { molar (weight) } \\
\text { monomer ratio in } \\
\text { backbone / grafts } \\
\text { from } \\
\text { feed monomer } \\
\text { composition }\end{array}$} & \multirow{2}{*}{$\begin{array}{l}\text { molar (weight) } \\
\text { monomer ratio in } \\
\text { backbone / grafts } \\
\text { from } \\
\text { copolymer } \\
\text { composition }\end{array}$} \\
\hline & Graft & $\begin{array}{l}\text { Graft } \\
\text { copolymer }\end{array}$ & & \\
\hline PD-N & $\begin{array}{l}\mathrm{M}_{\mathrm{n}}=23.0 \mathrm{~kg} / \mathrm{mol} \\
Đ \cong 1.4\end{array}$ & $\begin{array}{l}\mathrm{M}_{\mathrm{n}}=370 \mathrm{~kg} / \mathrm{mol} \\
Đ \cong 2.6\end{array}$ & $1.14 / 1(\underline{50 / 50})$ & $1.44 / 1(\underline{56 / 44})$ \\
\hline PN-D & $\begin{array}{l}\mathrm{M}_{\mathrm{n}}=14.5 \mathrm{~kg} / \mathrm{mol} \\
Đ \cong 1.5\end{array}$ & $\begin{array}{l}\mathrm{M}_{\mathrm{n}}=460 \mathrm{~kg} / \mathrm{mol} \\
Đ \cong 2.7\end{array}$ & $\mathbf{1} / 1.14(\underline{\mathbf{5 0} / 50})$ & $1.12 / 1(\underline{56 / 44})$ \\
\hline
\end{tabular}

After coupling the amino end-group with a large excess of acrylic acid, and assuming a quantitative yield of this reaction, we can see that the level of macromonomer incorporation in the graft copolymer is relatively high for the two macromonomers. ${ }^{1} \mathrm{H}$ NMR analysis gives a relative conversion of about $80 \%$ for the copolymerization of vinyl-terminated PDMA and PNIPA with respect to the other comonomer. Starting from the same feed monomer/(macromonomer) weight ratio $(\mathbf{5 0 / ( 5 0 )})$, the final weight composition of graft architectures is 56/(44) for both PN-D and PD-N. Even if these topologically inverse copolymers do not have exactly the same DMA/NIPA weight content, their equilibrated composition remains in good agreement with our initial goal as it provides a good compromise between solubility and aggregation at high temperature. Moreover, the high molar mass of the copolymer chains $\left(\mathrm{M}_{\mathrm{n}} \sim 400 \mathrm{~kg} / \mathrm{mol}\right)$ is favorable for the physical gel formation, as high molar mass means 1) low overlap concentration with the possibility to develop a percolated network at low concentration, and 2) a higher number of side-chains per macromolecule (between 8 and 12 in average for PD-N and PN-D) increasing the probability of inter-chain contacts. 


\section{Thermothickening behavior: sol/gel transition}

As shown in Figure 3, the two copolymer solutions studied at $3 \mathrm{wt} \%$ in the linear regime exhibit very similar thermothickening properties.

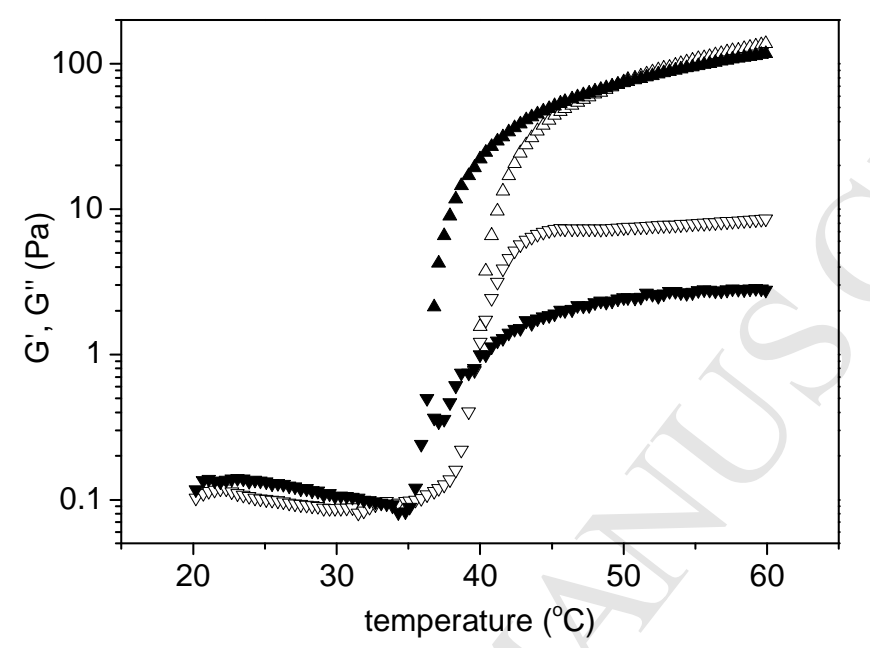

Figure 3. Temperature dependence of dynamic moduli ( $\boldsymbol{\Delta} \triangle$ for G' and $\boldsymbol{\nabla} \nabla$ for G' $)$ of PD-N (hollow symbols) and PN-D (filed symbols) aqueous solutions $(\mathrm{Cp}=3 \mathrm{wt} \%, \mathrm{f}=1 \mathrm{~Hz}$, heating rate $\left.=2{ }^{\circ} \mathrm{C} \cdot \mathrm{min}^{-1}\right)$.

At low temperature, typically below $35^{\circ} \mathrm{C}$, the backbone and the side chains are soluble in water and the copolymer solutions are mainly fluids with a very weak elastic contribution that is negligible and not measurable in our conditions. In this range of temperature the complex viscosity (see Figure S1 in supporting information), which is also the Newtonian viscosity at this frequency, decreases smoothly following an Arrhenius dependence. When the transition takes place, above $\mathrm{T}_{\mathrm{as}}=35^{\circ} \mathrm{C}$, PNIPA sequences start to self-associate giving rise to a sol/gel transition with a huge increase of elasticity, mainly between 35 and $45{ }^{\circ} \mathrm{C}$. Then at high temperature, $\left(\mathrm{T}>45-50{ }^{\circ} \mathrm{C}\right)$, well above the phase transition, the dynamic moduli and particularly the elastic one still increases slightly with temperature. In these conditions, the copolymer solutions behave as elastic gels with a very weak frequency dependence of the 
modulus and very long relaxation times which are out of scale in these experiments (see Figure $\mathbf{S 2}$ in supporting information). Here, we have to mention that the associating process is totally reversible with temperature with almost no hysteresis in the conditions of the study (see Figure S1). Interestingly, the two graft copolymers display very similar thermothickening properties that emphasize at the first order a common self-assembling process despite their inverse topologies. The main difference that can be underlined from Figure 3 is the rise of the elastic modulus that takes place a few degrees before for PN-D solution compared to PD-N. From another macroscopic point of view, the two copolymer solutions, initially transparent, remain translucent above the association temperature but more whitish for PN-D. By comparison, graft copolymers prepared by grafting shorter PNIPA side chains onto well water-soluble backbones like poly(sodium acrylate) or polyacrylamide remain totally transparent, even at high temperature and for high fraction of responsive stickers [23, 31-32].

\section{Phase transition}

The LCST-type phase transition of PNIPA in aqueous solutions is a very well-known phenomenon that has been widely reported in the literature [24,33]. At low temperature, PNIPA chains are soluble in water and exhibit a coiled conformation in order to maximize their hydrogen bonds with water molecules. Crossing the transition temperature, the chains start to undergo a sharp coil-to-globule transition in water, changing from hydrophilic state to hydrophobic one. During demixing, energy is required to disrupt the interactions between water molecules and amide groups and the phase transition of PNIPA is an endothermic process that can be easily followed by calorimetry. For instance, DSC experiments have shown that the characteristic parameters of the transition, typically the temperature and the transition enthalpy, are strongly coupled to the structure of the chain (molar mass, chemical 
composition and topology) and to the environmental conditions ( $\mathrm{pH}$, ionic strength, cosolvent ...) [24,33-35]. A typical thermogram is given in inset of Figure 4 for a 3 wt $\%$ aqueous solution of PN-D, along with the transition enthalpies $(\Delta \mathrm{H}$ in $\mathrm{kJ} / \mathrm{mol}$ of NIPA) of PN-D and PD-N solutions obtained after integration of endotherms.

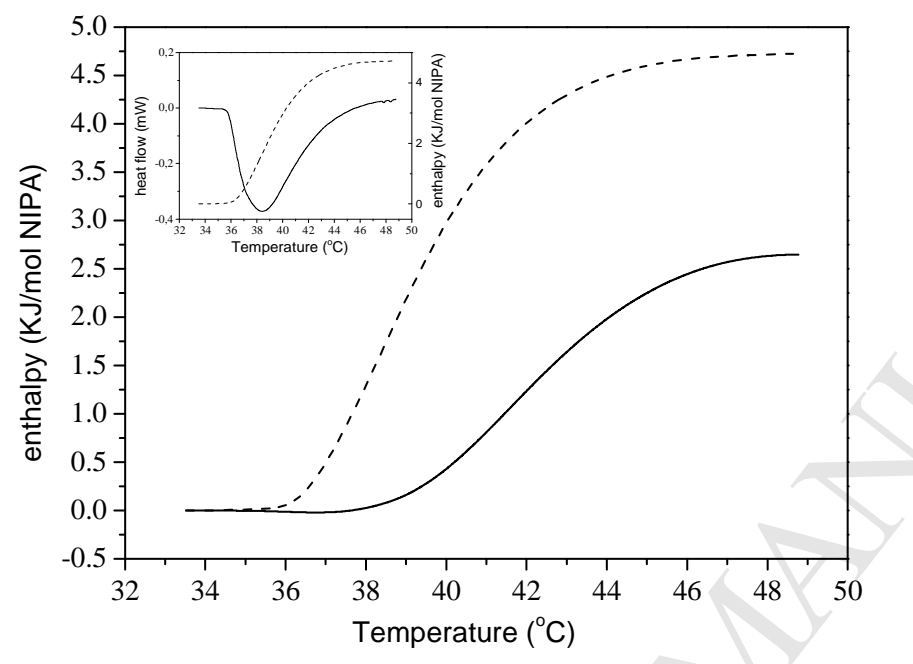

\section{Figure 4}

DSC analysis of PN-D (dash line) and PD-N (solid line) aqueous solution $(\mathrm{C}=3 \mathrm{wt} \%$, heating rate $\left.=2{ }^{\circ} \mathrm{C} \cdot \mathrm{min}^{-1}\right)$. The thermogram of PN-D (heat flow vs temperature) and its integration (cumulated enthalpy) are shown in inset.

The two copolymer solutions are characterized by a rather broad endotherm that spans over $10{ }^{\circ} \mathrm{C}$ as already observed for the viscoelastic transition in Figure 3. The broadness of the transition does not originate from the relatively high heating rate applied in DSC $\left(2{ }^{\circ} \mathrm{C} \cdot \mathrm{min}^{-1}\right)$, since similar thermograms were obtained at lower rates. For instance, $\mathrm{T}_{\mathrm{as}}$ and transition width decrease of approximately $1{ }^{\circ} \mathrm{C}$ by decreasing the heating rate from 2 to $0.5^{\circ} \mathrm{C} \cdot \mathrm{min}^{-1}$ while the transition enthalpy remains unchanged. The transition broadness probably arises from the relatively low molar mass of PNIPA sequences and their dispersity index but the topology of PD-N and PN-D, alternating PNIPA with hydrophilic PDMA inside the same covalent structure, certainly accounts for this behavior. As we can see from Figure 4, similar endotherms were obtained for both copolymers upon increasing temperature but the PN-D sample with the PNIPA backbone definitely shows the highest enthalpy $(4.7 \mathrm{~kJ} / \mathrm{mol}$ NIPA) and the lowest transition temperature $\left(36^{\circ} \mathrm{C}\right)$. By comparison, the transition of the PD-N 
solution starts at slightly higher temperature $\left(\sim+2{ }^{\circ} \mathrm{C}\right)$, around $38^{\circ} \mathrm{C}$, with an enthalpy of 2.6 $\mathrm{kJ} / \mathrm{mol}$ NIPA: the architecture of PD-N with PNIPA as pendant chains does not favor the association process between grafted chains that are not topologically close to each other. By comparison, the PNIPA precursor of the PDN copolymer displays a lower association temperature $\left(\mathrm{T}_{\mathrm{as}}=36{ }^{\circ} \mathrm{C}\right)$ and a higher transition enthalpy $(\Delta \mathrm{H}=4.3 \mathrm{~kJ} / \mathrm{mol}$ NIPA) at the same relative concentration. This comparison supports the idea that there is some energetic barrier in the association process due to the steric hindrance from the water-soluble backbone.

Complementary experiments have been carried out by ${ }^{1} \mathrm{H}$ NMR as a function of temperature. From the series of NMR spectra obtained between 15 and $55^{\circ} \mathrm{C}$ with the PD-N solution (Figure 5a), we can see that the signal of methyl groups of DMA, around $3 \mathrm{ppm}$, becomes to broaden with increasing temperature but its area remains almost unchanged or just slightly decreases with increasing temperature as reported in Figure 5b.
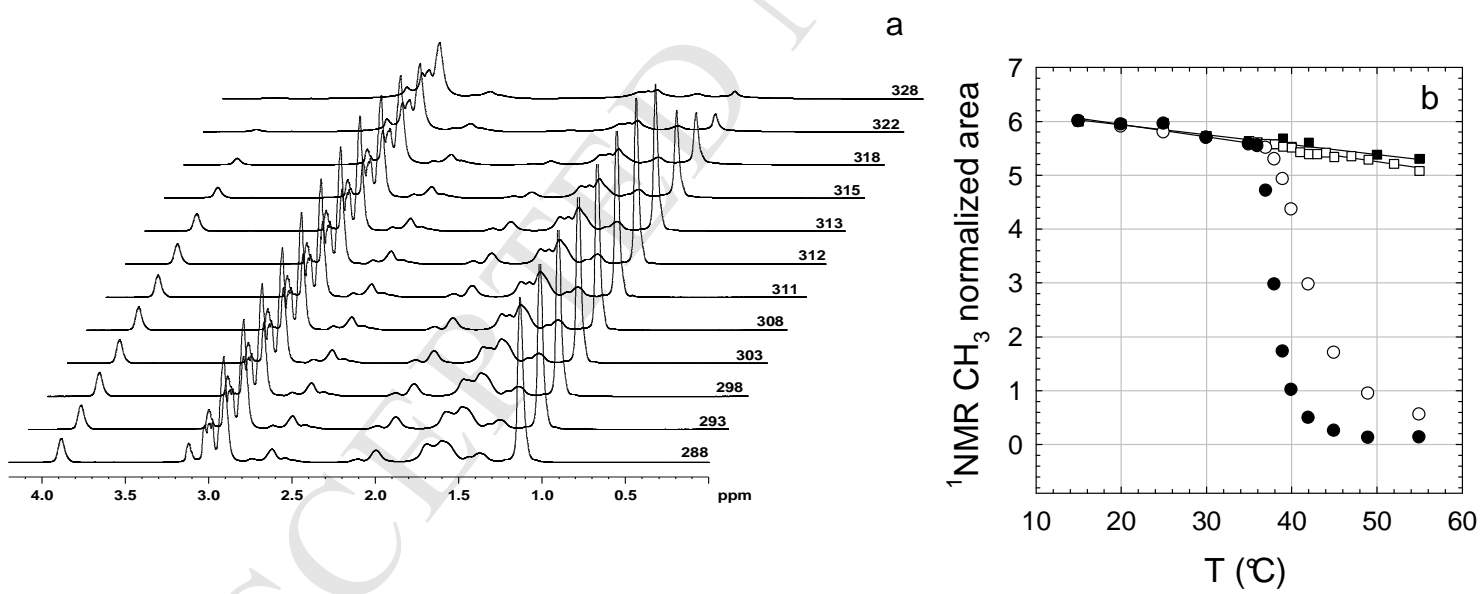

Figure 5. (a) Temperature variation of ${ }^{1} \mathrm{H}$ NMR spectrum of PD-N and (b) normalized area of $\mathrm{CH}_{3}$ signal from DMA (square) and NIPA (circle) of PD-N (hollow symbols) and PN-D (filled symbols) aqueous solutions $\left(\mathrm{C}=3 \mathrm{wt} \%, \mathrm{D}_{2} \mathrm{O}\right)$.

In the same conditions, the signals of methyl and methine groups of NIPA, observed at 1 and 4 ppm respectively, show a dramatic decrease above $35^{\circ} \mathrm{C}$ and practically disappear at $55^{\circ} \mathrm{C}$. 
This feature, that has been widely reported with PNIPA copolymers or gels [36-39], can be assigned to the formation of a solid-like rich-PNIPA phase close to its glass transition [24] and where the motions of the functional groups are strongly reduced. As shown in Figure 5b, the PN-D sample undergoes a more abrupt transition than PD-N as already described by DSC. The main conclusion that holds for the two copolymer solutions, is that at high temperature most of PNIPA sequences are aggregated into PNIPA-rich domains of low mobility. The low exchange rate of PNIPA sequences at high temperature is also responsible for the "covalent network" pattern obtained with the two copolymers in the gel state (Figure S2 in supporting information).

\section{Nanostructure from small angle neutron scattering}

Scattering experiments have been performed at different temperatures with copolymer solutions in $\mathrm{D}_{2} \mathrm{O}$. As shown in supporting information (Figure S3), there is no significant modification of the thermodynamic behavior of PNIPA replacing $\mathrm{H}_{2} \mathrm{O}$ with $\mathrm{D}_{2} \mathrm{O}$; or at least the difference remains within $1{ }^{\circ} \mathrm{C}$ as already reported in the literature [40]. As shown in Figure 6a, the thermo-association process of PN-D in aqueous solution takes place abruptly upon heating. As soon as the transition temperature is reached, above $33{ }^{\circ} \mathrm{C}$ as measured in the sample holder, the scattering intensity immediately increases on the whole $q$-range figuring fluctuation concentrations related to the phase separation of PNIPA. With increasing temperature, the intensity still increases with a characteristic length that can be more easily observed at higher polymer concentrations (see Figure 7a). This means that hydrophilic PDMA side-chains efficiently stabilize the phase separation process of PNIPA backbone at a microscopic level; the characteristic size of the micro-phase separation being $D=2 \pi / q_{\max }$. Concurrently, as soon as the transition takes place, the Porod's law $\left(\mathrm{I}(q) \sim q^{-4}\right)$ is observed in 
the asymptotic regime, in agreement with the formation of a biphasic system with sharp interfaces.
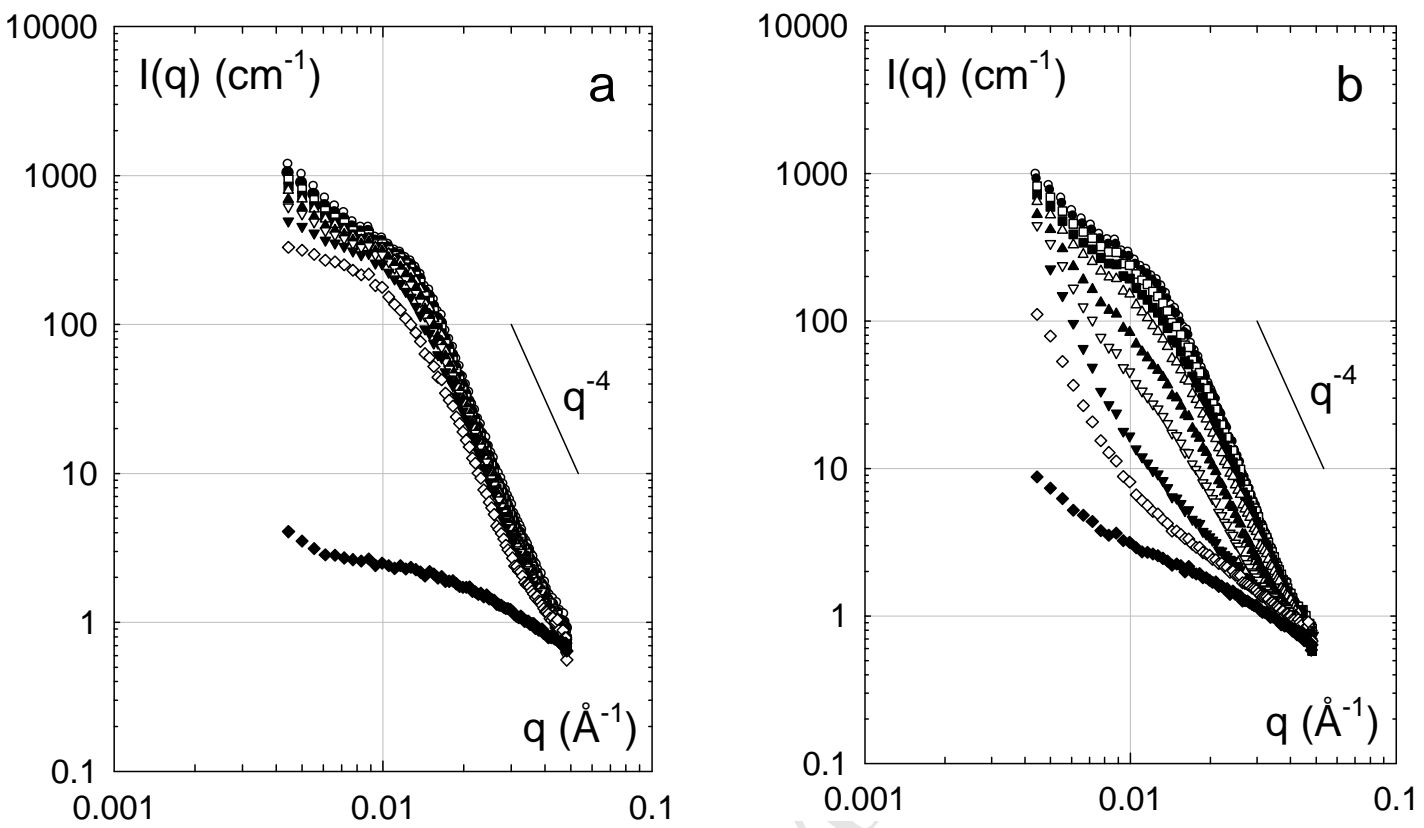

Figure 6. Double logarithmic plots of the scattering intensity of $3 \mathrm{wt} \%$ PN-D (a) and PD-N (b) solutions at different temperatures $\left(\mathrm{T}^{\circ} \mathrm{C}\right)$ : $33.0(\diamond), 35.0(\diamond), 36.0(\boldsymbol{\nabla}), 37.0(\nabla), 38.5$ $(\mathbf{\Delta}), 40.0(\triangle), 43.0(\mathbf{\square}), 45.5(\square), 51.0(\bullet)$ and $57.5(\bigcirc)$.

By comparison, the thermo-association process of $\mathrm{PD}-\mathrm{N}$ in aqueous solution takes place more progressively upon heating. As soon as the transition temperature is reached, the scattering intensity starts to increase at low $q$ with the formation of heterogeneities at long distance. Then, above $35{ }^{\circ} \mathrm{C}$, the scattering intensity increases progressively and its q-dependence finally reaches the Porod's law at high temperature, above $45-50^{\circ} \mathrm{C}$. These scattering patterns, typical from microphase separation, have been already described for water-soluble polymers grafted with PNIPA or other LCST side-chains $[18,41]$ and for weakly charged PNIPA gels [42] or linear copolymers [29]. From Figure 7, we notice that at high temperature the two microphase separated systems are characterized by similar correlation lengths, about $500 \AA$. Nevertheless, the PN-D solution clearly shows a higher upturn at low q (higher osmotic 
compressibility) underlining the presence of concentration fluctuations at closer distance. This can be related to a decrease of the contribution of PDMA side-chains to steric repulsions with increasing temperatures.
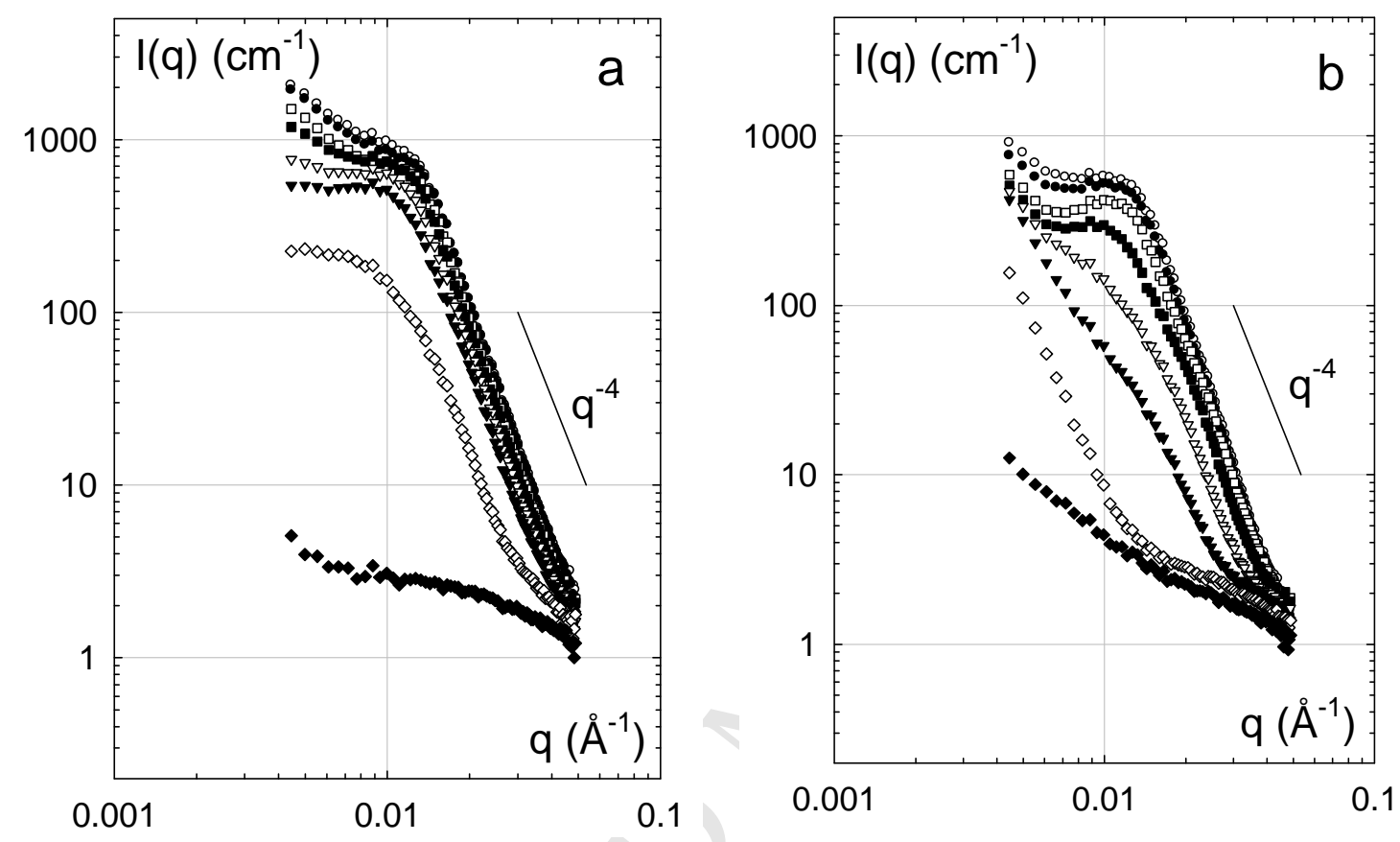

Figure 7. Double logarithmic plots of the scattering intensity of $8 \mathrm{wt} \% \mathrm{PN}-\mathrm{D}$ (a) and PD-N (b) solutions at different temperatures $\left(\mathrm{T}^{\circ} \mathrm{C}\right)$ :

$29.0(\diamond), 33.0(\diamond), 35.0(\nabla), 36.0(\nabla), 38.5(\square), 43.0(\square), 51.0(\bullet)$ and $57.5(\bigcirc)$.

In order to get more details on the formation of PNIPA domains, the experimental invariant $\left(Q_{\text {exp }}\right)$ was determined from the scattering curve:

$$
Q_{\exp }=\int_{0}^{\infty} q^{2} I(q) d q
$$

In the case of incompressible biphasic systems, as it is for PNIPA copolymer solutions above their transition temperature, the invariant is in theory a constant that only depends on volume fraction $\left(\phi_{i}\right)$ and difference between the scattering length densities (the contrast $\left(\rho_{i}\right)$ ) of the two phases: 


$$
Q_{t h}=2 \pi^{2}\left(\rho_{1}-\rho_{2}\right)^{2} \phi_{1} \phi_{2}
$$

As the contrast $\left(\rho_{1}-\rho_{2}\right)^{2}$ itself is a function of the scattering length density and volume fraction of the phase component, it is then possible to estimate the composition of the segregated phase. Here we assume that PDMA segments are totally excluded from the segregated phase and remain in the outer medium with water and possibly a fraction of non aggregated PNIPA chains $\left(1-\mathrm{f}_{\mathrm{PNIPA}}\right)$. On this basis, two extreme hypotheses can be considered:

1) all PNIPA segments are embedded into micro-domains $\left(f_{\mathrm{PNIPA}}=1\right)$ at a volume fraction $\phi_{\mathrm{PNIPA}}<1$; considering the presence of water inside the aggregates,

2) only a fraction of PNIPA chains $\left(f_{\mathrm{PNIPA}}<1\right)$ contributes to the formation of dry aggregates $\left(\phi_{\mathrm{PNIPA}}=1\right)$.

As shown in supporting information (Figure S4), the extrapolated values of $f_{P N I P A}$ times $\phi_{\text {PNIPA }}$ do not strongly differ from one hypothesis to the other. Considering that all the other situations lie between these two limits, we have used the average value of $\mathrm{f}_{\mathrm{PNIPA}}{ }^{*} \phi_{\mathrm{PNIPA}}$ in the following discussion to describe the "level of the phase separation". Such data treatment is exemplified in Figure 8 with PN-D and PD-N solutions at 3 and 8 wt $\%$ in water. As we can see, the self-assembling of PNIPA sequences mainly takes place between 35 and $45^{\circ} \mathrm{C}$ where the level of the phase separation reaches about 60 to $70 \%$, with a relative accuracy of about 10 $\%$. Above $45{ }^{\circ} \mathrm{C}$, the extent of the phase segregation increases more gently up to $70-80 \%$ at $60{ }^{\circ} \mathrm{C}$. These results are in good agreement with previous data obtained by DSC, ${ }^{1} \mathrm{H}$ NMR and rheology where the PD-N sample (with PNIPA grafts) was shown to self-associate more gradually with temperature compared to the inverse PN-D structure (with PNIPA backbone). Above $45^{\circ} \mathrm{C}$, the phase transition is almost over for PN-D, as seen from DSC and NMR 
$\left(f_{\text {PNIPA }} \cong 1\right)$, and the dynamic moduli increase more gently. This can be correlated with a small increase of the PNIPA concentration inside the microdomains, with or without some reorganisation at the mesoscopic level. For the PD-N sample, this strong segregation regime where all PNIPA side-chains are embedded into aggregates, is observed only at higher temperature; typically above $55^{\circ} \mathrm{C}$. In these conditions where most PNIPA side-chains participate to the association behavior the invariant analysis shows that the microdomains are not totally dry and contain around 20 to $30 \mathrm{wt} \%$ of water. This result is in good agreement with the literature that generally describes the phase transition of PNIPA by the formation of glassy-like aggregates; the glass transition of the PNIPA/water system being close to room temperature for PNIPA volume fraction around $70 \mathrm{wt} \%^{[21]}$.

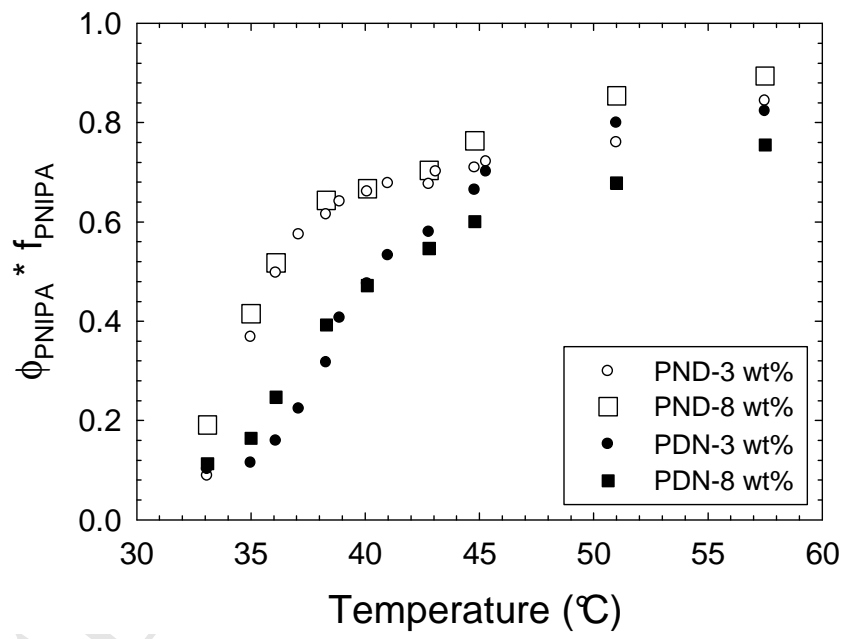

Figure 8. Temperature dependence of the PNIPA-rich phase with $\mathrm{f}_{\mathrm{PNIPA}}$ the fraction of PNIPA embedded in the segregated phase and $\phi_{\mathrm{PNIPA}}$ their volume fraction estimated from the SANS invariant analysis .

From the asymptotic behavior obtained at high temperature $\left(\mathrm{I}(q) \sim q^{-4}\right)$, the total interface area of microdomains $(S)$ in the scattering volume $(V)$ can be calculated using the following relation : 


$$
S_{s p e} \cong \frac{S}{V \phi_{2} \phi_{1}}=\frac{\pi}{Q} \lim _{q \rightarrow \infty} q^{4} I(q)
$$

As $\mathrm{V} \phi_{2}$ is the total volume of microdomains and $\phi_{1}$ is close to 1 for all the copolymer solutions in the segregated regime, the left hand term in equation $\{3\}$ can be identified with the specific surface of PNIPA microdomains $\left(S_{s p e}\right)$. Interestingly, at high temperature, this specific surface is almost the same whatever the topology (PN-D or PD-N) and the concentration of copolymers $\left(\mathrm{C}_{\mathrm{p}}=3\right.$ and $\left.8 \mathrm{wt} \%\right): S_{\text {spe }} \cong 0.022 \AA^{-1}$. One could see perhaps some close relation with the internal structure of the Yin and Yang copolymers having similar PDMA/PNIPA composition (close to 50/50). While the specific surface can be easily calculated, the real size of the microphase separated domains cannot be precisely determined. Indeed domains size is closely related to the possible morphology : $S_{2} / V_{2}$ being equal to $1 / \mathrm{t}$ for platelets of thickness $t$ ( $t=46 \AA$ ), 2/R for cylinders of radius $R(R=93 \AA), 3 / R$ for spheres of radius $\mathrm{R}(\mathrm{R}=140 \AA)$ and $4 / \xi$ or $6 / \xi$ for various random biphasic models with a correlation distance $\xi(\xi=186 \text { or } 280 \AA \text { A, respectively })^{[43-45]}$.

\section{Concentration dependence}

As shown in supporting information (Figure S5), there is no major difference concerning the thermodynamic behavior as a function of the copolymer concentration. Indeed, for both series of copolymer solutions, the same endotherm with similar association temperature and enthalpy were obtained whatever is the concentration investigated between 1 and $10 \mathrm{wt} \%$. Looking at the macroscopic properties, the conclusion is rather different. For simplicity we have plotted in Figure 9 the complex viscosity versus the temperature as this single parameter $\eta^{*}$ is proportional to both loss and storage moduli in the liquid (solution) and solid (gel) states, respectively. Working at low concentration ( $1 \mathrm{wt} \%)$, in the semi-dilute regime, the PD$\mathrm{N}$ solution exhibits a very weak increase of viscosity above $40{ }^{\circ} \mathrm{C}$ (about 1 decade) followed 
by thermo-thinning at higher temperatures. In this case, the elastic modulus remains negligible at all temperatures and the solution is mainly viscous. While $1 \mathrm{wt} \%$ is too low to form a percolating network with the PD-N copolymer, this situation becomes more favorable at higher concentrations as a dramatic increase of elasticity and complex viscosity is observed from $2 \mathrm{wt} \%$. In the case of the PN-D sample, the formation of an elastic network at high temperature is obtained at higher concentration than PD-N, typically $3 \mathrm{wt} \%$. Indeed, the solution at $1 \mathrm{wt} \%$ does not really show any thermoviscosifying effect while, at $2 \mathrm{wt} \%$, only a weak thermothickening is observed between 35 and $40{ }^{\circ} \mathrm{C}$ followed by a collapse of the macromolecular assembly at higher temperature.
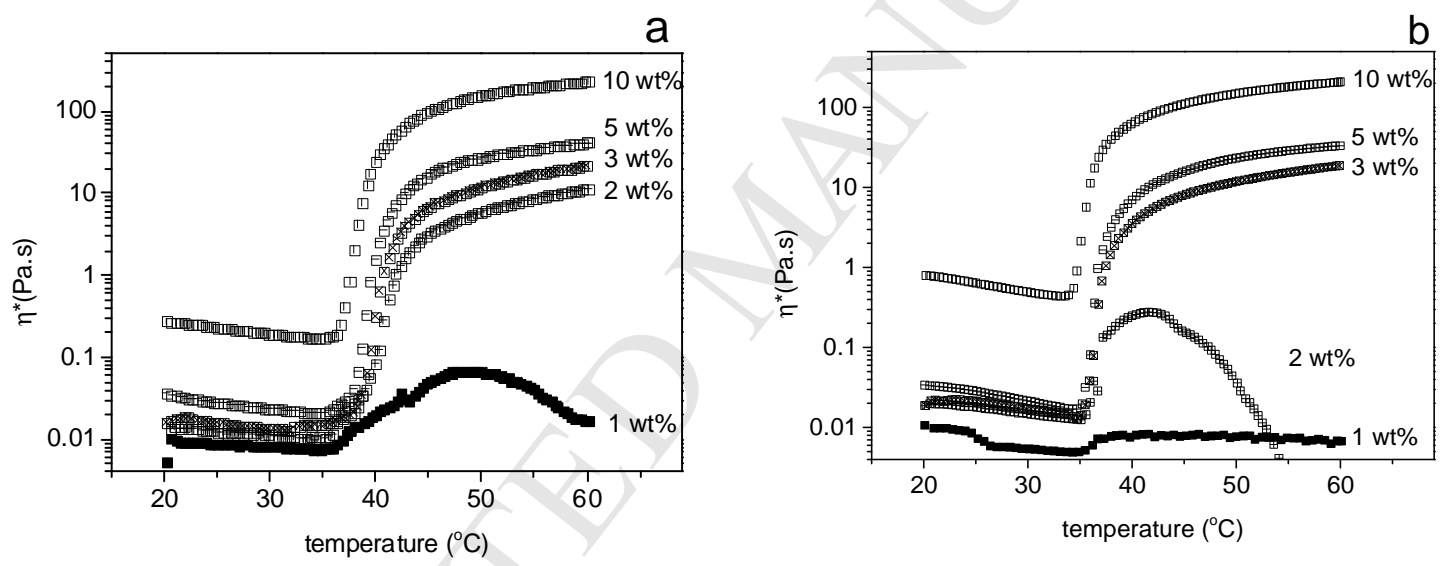

Figure 9. Temperature dependence of viscoelastic properties of PD-N (a) and PN-D (b) aqueous solutions as a function of polymer concentration $\left(\mathrm{f}=1 \mathrm{~Hz}\right.$, heating rate $\left.=2{ }^{\circ} \mathrm{C} \cdot \mathrm{min}^{-1}\right)$.

Even if both the level of viscosity and concurrently the level of overlapping of copolymers PD-N and PN-D are similar at low temperature and the average molar mass of PN-D is higher than PD-N, we have to consider that contrary to PD-N, the PN-D sample undergoes a strong collapse of its pervaded volume at the transition threshold. There is consequently an important competition between intra- and inter-chain associations in the vicinity of the transition temperature and concentration will have a huge impact on the connectivity of the self- 
assembly. Conversely, as the PDMA backbone has a weak temperature dependence, we can reasonably assume that inter-chain associations will become favorable as soon as the overlapping of the chains will be effective in the low temperature range. Whatever is the copolymer, stable and thermo-reversible gels are readily obtained above the critical percolation concentration.

\section{Addition of salt}

It is well known that the addition of salts in aqueous media generally destabilizes the hydration state of LCST polymers and leads to a decrease of their transition temperature. This effect, known as salting-out, has been extensively used to control the phase separation on a very broad range of temperature [17] that can extend well beyond $\Delta \mathrm{T}=100{ }^{\circ} \mathrm{C}$. In the present study we have used potassium carbonate which is known to strongly modify the solubility of PNIPA. As shown in Figure 10, the addition of $\mathrm{K}_{2} \mathrm{CO}_{3} 0.3 \mathrm{M}$ decreases the association temperature from $36-38{ }^{\circ} \mathrm{C}$ to $23{ }^{\circ} \mathrm{C}$ in a very similar manner for the two copolymers.

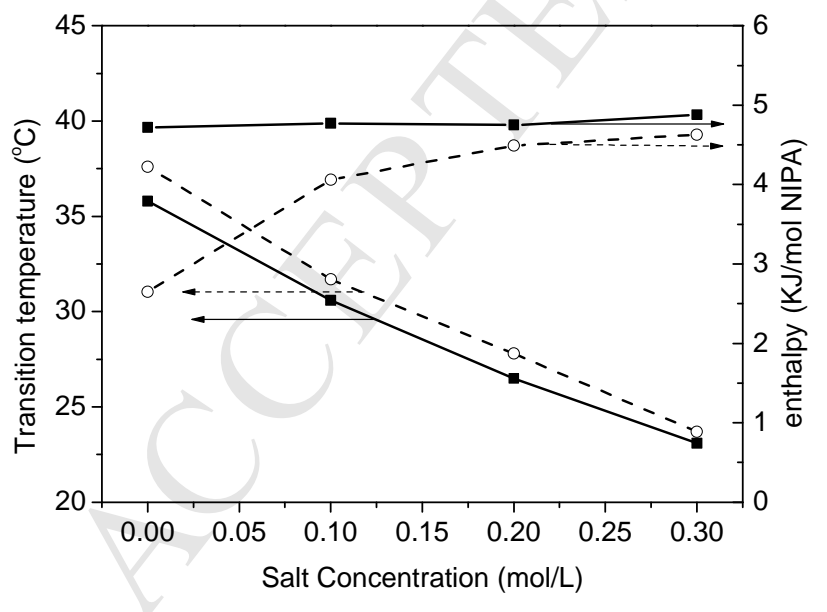

Figure 10

Influence of added potassium carbonate on the association behavior of $3 \mathrm{wt} \%$ aqueous solutions of PD-N $(\mathrm{O}$ and dash line) and PN-D ( $\mathbf{\square}$ and solid line). (heating rate $=2{ }^{\circ} \mathrm{C} \cdot \mathrm{min}^{-1}$ )

We can also notice that the addition of salt increases the transition enthalpy of the PD-N sample that reaches about $4.5-4.7 \mathrm{~kJ} / \mathrm{mol}$ of NIPA like the PN-D copolymer and the graft PNIPA precursor as well. We can assume that the dehydration process of PNIPA grafts with 
formation of intra-molecular hydrogen bonding is more efficient at high temperature in the presence of salt.

The viscoelastic properties of the same solutions, reported in Figure 11, display a dramatic difference between the two copolymers. In the case of PD-N, with PNIPA grafts, the addition of salt mostly shifts the association temperature along the $\mathrm{x}$-axis towards lower temperature as observed from DSC. The complex viscosity or dynamic moduli only show a weak decrease with added salt that can be related to a slight deswelling of the PDMA backbone as the quality of solvent becomes worse. This behavior is well documented with solutions of poly(sodium acrylate) grafted with poly(ethylene oxide) which have been studied on a very high range of $\mathrm{K}_{2} \mathrm{CO}_{3}$ concentrations (up to 1.2 molar) [46]. By comparison, the impact of salt on a $3 \mathrm{wt} \%$ PN-D solution is much more critical as the percolation and thermothickening properties rapidly vanish. Indeed, if addition of salt effectively decreases the association temperature, only a weak thermothickening is observed with $\mathrm{K}_{2} \mathrm{CO}_{3} 0.1 \mathrm{M}$ with a decrease of the moduli at high temperature of more than one decade compared to the same solution in pure water. Beyond these conditions, the formation of non percolating clusters in the solution gives rise to an unstable viscous behavior. Similarly, neutron scattering data show a better stability of the micro-phase separated PD-N sample in the presence of salt, compared to PN-D (see Figure S6 in supporting information). These experiments, probing the structure at a local scale, point out a large increase of the characteristic length of microphase separation (more than 50\%) when $\mathrm{K}_{2} \mathrm{CO}_{3} 0.3 \mathrm{M}$ is added into the PN-D solution while this characteristic size remains almost unchanged with the PD-N sample. In this later case the main difference arises from the formation of a more concentrated PNIPA phase at high temperature as already underlined by DSC thermograms. Even if there is a lack of information at the mesoscopic scale, that could bridge neutron scattering to rheology, we can assume that the high sensitivity of the PNIPA backbone in the vicinity of the phase transition and its lower stability in the presence of salt 
are responsible for the weak thermothickening performance observed at $3 \mathrm{wt} \%$. This problem can nevertheless be avoided by working at higher polymer concentration where inter-chain association will dominate over the intra-molecular collapse occurring during the micro-phase separation (see Figure S7 in supporting information).
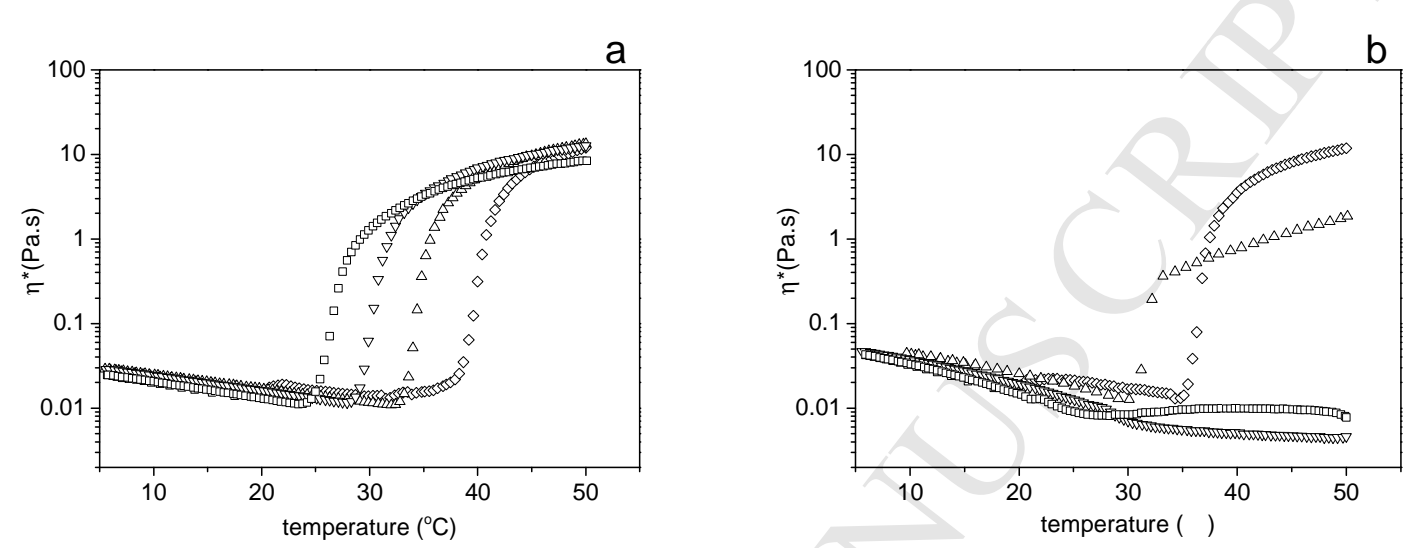

Figure 11. Influence of salt on viscoelastic properties of PD-N (a) and PN-D (b) aqueous solutions $\left(\mathrm{Cp}=3 \mathrm{wt} \%, \mathrm{f}=1 \mathrm{~Hz}\right.$, heating rate $\left.=2{ }^{\circ} \mathrm{C} / \mathrm{min}\right)$. $\mathrm{K}_{2} \mathrm{CO}_{3}$ concentrations: $0(\diamond), 0.1(\triangle), 0.2(\nabla)$ and $0.3 \mathrm{~mol} / \mathrm{L}(\square)$.

\section{Addition of surfactant}

The addition of ionic surfactant, either anionic such as SDS (sodium dodecyl sulfate) or cationic like CTAC (cetyltrimethyl ammonium chloride), is known to dramatically modify the phase transition of PNIPA derivatives in aqueous solution. In the case of SDS, it was proposed that above a critical aggregation concentration $(\sim 0.8 \mathrm{mM})$, that is well below the critical micelle concentration of SDS $(8.6 \mathrm{mM})$, surfactant micelles bound to PNIPA segments via hydrophobic interactions, forming polyelectrolyte necklaces that progressively hinder the formation of PNIPA aggregates at high temperatures [38,47-48]. Indeed, as shown in Figure 12, the addition of SDS into PD-N and PN-D solutions has the opposite effect of salt with an increase of the association temperature and a decrease of the transition enthalpy. A weaker segregation state at high temperature was also observed by ${ }^{1} \mathrm{H}$ NMR in the presence 
of $2.5 \mathrm{mM}$ of SDS (Figure S8 in supporting information). We can also mention that from 2D NOESY experiments (not shown here) it was emphasized that in the range of concentration studied, SDS molecules efficiently interact with NIPA units, as already reported in the literature [49], but not with DMA. Again the two copolymers behave very similarly from the thermodynamic point of view but their macroscopic properties are totally different at this polymer concentration.

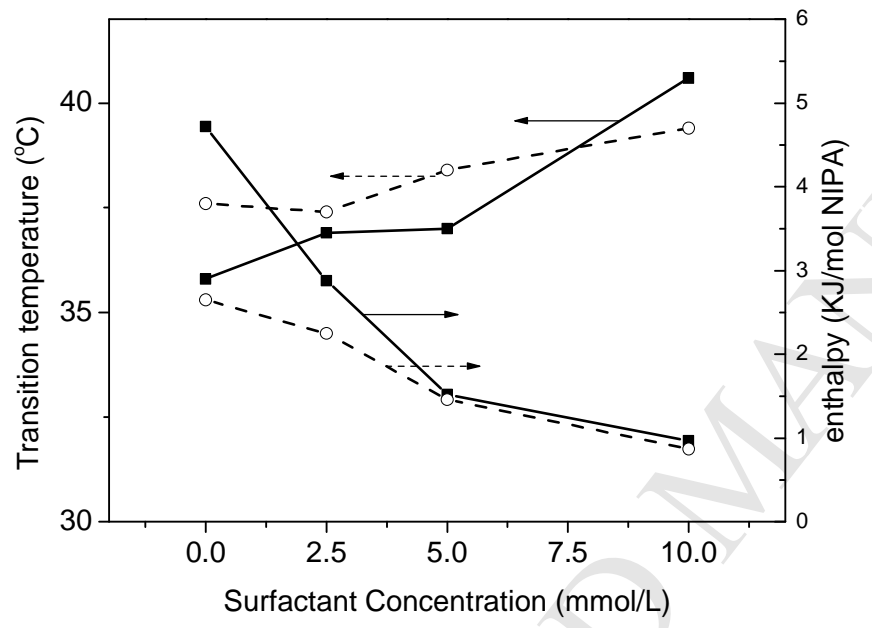

\section{Figure 12}

Influence of added SDS on the association behavior of $3 \mathrm{wt} \%$ aqueous solutions of PD-N ( $\bigcirc$ and dash line) and PN-D ( $\square$ and solid line). (heating rate $=2{ }^{\circ} \mathrm{C} \cdot \mathrm{min}^{-1}$ )

As shown in Figure 13, the viscoelastic properties of the PD-N solution is shifted to higher temperature with increasing SDS concentration in agreement with DSC data. Concurrently the thermothickening properties progressively decrease and we could expect to totally suppress the thermoassociation behavior at very high SDS concentrations, when all PNIPA chains will be saturated by surfactant micelles forming water-soluble polyelectrolyte necklaces [47]. Such behavior is expected at high temperature for weight ratio SDS/PNIPA (S/P) higher than 0.4 [38,47], i.e. SDS concentration higher than $20 \mathrm{mM}$ in our conditions. By comparison, the sol/gel transition is totally suppressed for the PN-D solutions, even for the lowest concentration of added surfactant $(2.5 \mathrm{mM}$, i.e. $\mathrm{S} / \mathrm{P} \cong 0.05)$. In this case, where the gelation threshold relies on the percolation of PNIPA aggregates, the solubilization of PNIPA chains 
or sequences with the formation of polyelectrolyte necklaces will be critical for the percolation process, especially at $3 \mathrm{wt} \%$ which is just above the concentration threshold. The neutron scattering data plotted in supporting information (see Figure S6) also indicate a higher sensitivity of the PN-D sample with added SDS as the characteristic length is reduced from about $15 \%, q_{\max }$ being shifted towards higher $q$ values. For the two samples, the relative concentration $\mathrm{f}_{\mathrm{PNIPA}} * \phi_{\mathrm{PNIPA}}$ that can be calculated from the invariant highlights a decrease of 10 to $20 \%$ when $2.5 \mathrm{mM}$ SDS is added, in very good agreement with DSC and NMR experiments (see Figure S8 in supporting information). As directly shown by NMR, this result can be attributed to the decrease of the number of PNIPA sequences that participate to the association process $\left(\mathrm{f}_{\mathrm{PNIPA}}<1\right)$.
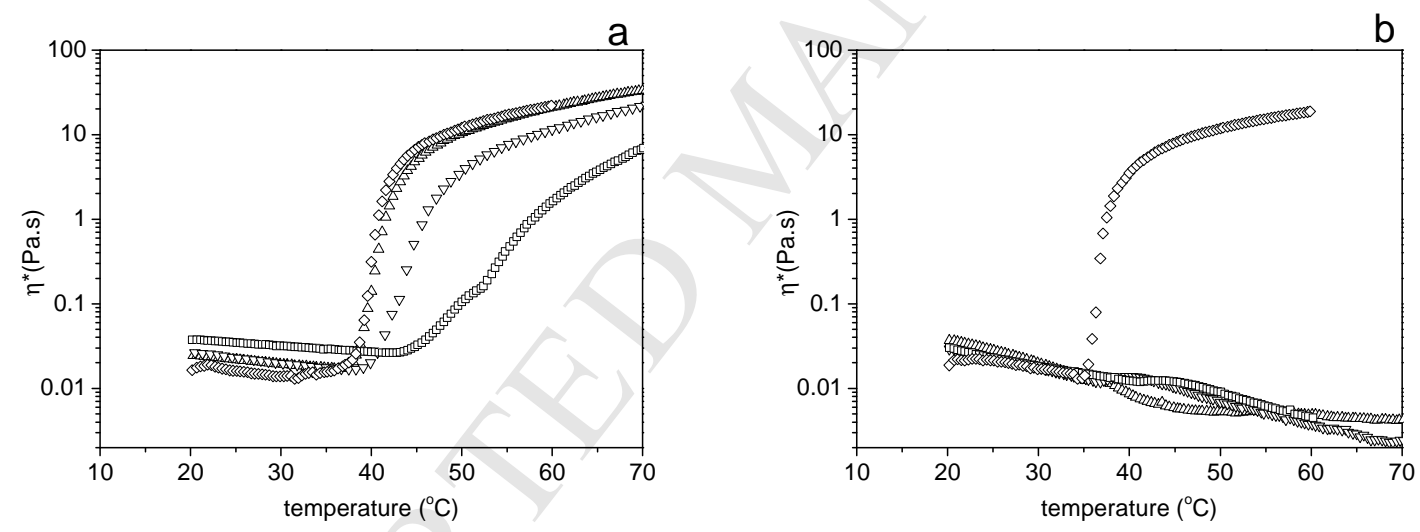

Figure 13. Influence of SDS on viscoelastic properties of PD-N (a) and PN-D (b) aqueous solutions $\left(\mathrm{Cp}=3 \mathrm{wt} \%, \mathrm{f}=1 \mathrm{~Hz}\right.$, heating rate $\left.=2{ }^{\circ} \mathrm{C} \cdot \mathrm{min}^{-1}\right)$. SDS concentrations: $0(\diamond), 2(\triangle), 5(\nabla)$ and $10 \mathrm{mM}(\square)$.

\section{Self-assembling in dilute solution}

Dynamic Light Scattering (DLS) has been used to investigate the variation of the size distribution profile of copolymer chains during the phase transition process. For that purpose very dilute solutions $(0.01 \mathrm{wt} \%)$ have been prepared at room temperature and the size of the 
copolymer chains was followed as a function of temperature. The results reported in Table 2 show that the PN-D chain with the PNIPA backbone has a high tendency to collapse upon heating. Its pervaded volume decreases 20 times between 25 and $55{ }^{\circ} \mathrm{C}$ but the collapsed conformation remains stable with a steric corona formed by PDMA side-chains.

\begin{tabular}{|c|c|c|c|c|c|}
\hline \multirow{2}{*}{ Solvent } & \multirow{2}{*}{$\mathbf{T}\left({ }^{\circ} \mathrm{C}\right)$} & \multicolumn{2}{|c|}{ Radius (nm) } & \multicolumn{2}{|c|}{ PDI } \\
\hline & & PN-D & PD-N & PN-D & PD-N \\
\hline $\mathrm{H}_{2} \mathrm{O}^{\mathrm{a}}$ & 25 & 37 & 33 & 0.25 & 0.25 \\
\hline $\mathrm{H}_{2} \mathrm{O}^{\mathrm{a}}$ & 35 & 29 & 25 & 0.29 & 0.26 \\
\hline $\mathrm{H}_{2} \mathrm{O}^{\mathrm{a}}$ & 45 & 17 & 47 & 0.06 & 0.24 \\
\hline $\mathrm{H}_{2} \mathrm{O}^{\mathrm{a}}$ & 55 & 14 & 36 & 0.04 & 0.25 \\
\hline $\mathrm{H}_{2} \mathrm{O}^{b}$ & 55 & 34 & - & 0.27 & - \\
\hline$\left[\mathrm{K}_{2} \mathrm{CO}_{3}\right] 0.1 \mathrm{M}^{\mathrm{a}}$ & 55 & 76 & 60 & 0.39 & 0.43 \\
\hline$[\mathrm{SDS}] 2.5 \mathrm{mM}^{\mathrm{a}}$ & 55 & 24 & 18 & 0.32 & 0.37 \\
\hline \multicolumn{6}{|c|}{$\begin{array}{l}\text { a/ Samples were prepared at concentration } 0.1 \mathrm{~g} / \mathrm{L} \text { at room temperature and used for } \\
\text { test at designate temperature directly. } \\
\text { b/ Samples were initially prepared at } 30 \mathrm{~g} / \mathrm{L} \text { at room temperature and left at } 55^{\circ} \mathrm{C} \text { for } \\
1 \mathrm{~h} \text {. Then the sample was diluted by water }\left(55^{\circ} \mathrm{C}\right) \text { and used for test at } 55^{\circ} \mathrm{C} \text {. }\end{array}$} \\
\hline
\end{tabular}

This result is in good agreement with the theoretical predictions of Borisov and coworkers concerning the conformation of comb-like copolymers upon inferior solvent strength for the main chain while the solvent remains good for the side chains [49,50]. Indeed, in the case of weakly asymmetric graft copolymers, as it is for the PN-D sample where the size of the individual side chain in good solvent is close to the average size of the spacer under $\Theta$ conditions, they predict the formation of stable collapsed structures (necklace of star-like micelles) in poor solvent conditions for the backbone. The main difference between our copolymers and the theoretical predictions is that dynamics is highly reduced in the case of PNIPA assemblies.

If the phase transition is activated in the semi-dilute regime (3 wt $\%)$ prior to dilution, aggregates of higher polydispersity are obtained, showing their propensity to form intermolecular aggregates at higher concentration. By comparison, PD-N chains studied in dilute 
conditions show larger dimensions above the transition temperature with the formation of both intra- and inter-molecular associations. This behavior is very similar to the self-assembly of polysoaps reported by Borisov et al. [51] in dilute solutions where bridging attractions are responsible for inter-chain aggregation and macrophase separation. Although addition of salt favors the formation of larger inter-chain aggregates, the opposite tendency is observed in the presence of SDS at high temperature.

\section{DISCUSSION}

As shown in this work, the solution properties of the two copolymers PD-N and PN-D, having similar compositions but inverse topologies, display close resemblance and critical differences in aqueous media.

Water-soluble copolymers grafted with LCST stickers have been well studied during the last two decades and their structure determined from scattering techniques is generally described with the formation of LCST microdomains connected by water-soluble macromolecular backbones. The exact structure strongly depends on the nature and number of the LCST stickers, but also on the nature of the backbone which could be polyelectrolyte or neutral, in very good solvent or in theta-solvent. All these parameters will have critical impacts on the microphase separation as they will control the size and the stability of domains. In the case of PDMA which could be considered in good solvent in water, the neutron scattering data obtained with PD-N solutions show a rather continuous process for the microphase separation with the formation of an increasing number of PNIPA aggregates of increasing concentration that finally leads to sharp interfaces with the outer medium at high temperature. As PNIPA chains are relatively short and chemically anchored on the hydrophilic backbone, they are less prompt to self-associate. The self-assembling is then a relatively continuous process taking 
place mainly between 40 and $55^{\circ} \mathrm{C}$ as shown by DSC, NMR and SANS. In the schematic description of the self-assembling of PD-N sample given in Figure 14, the main idea is that the phase transition of PNIPA side-chains (from coil to globule) leads to a micro-phase separated structure where the rich PNIPA aggregates, drawn as spheres for simplicity, can be either randomly dispersed within the PDMA/solvent matrix or connected forming a bicontinuous morphology.

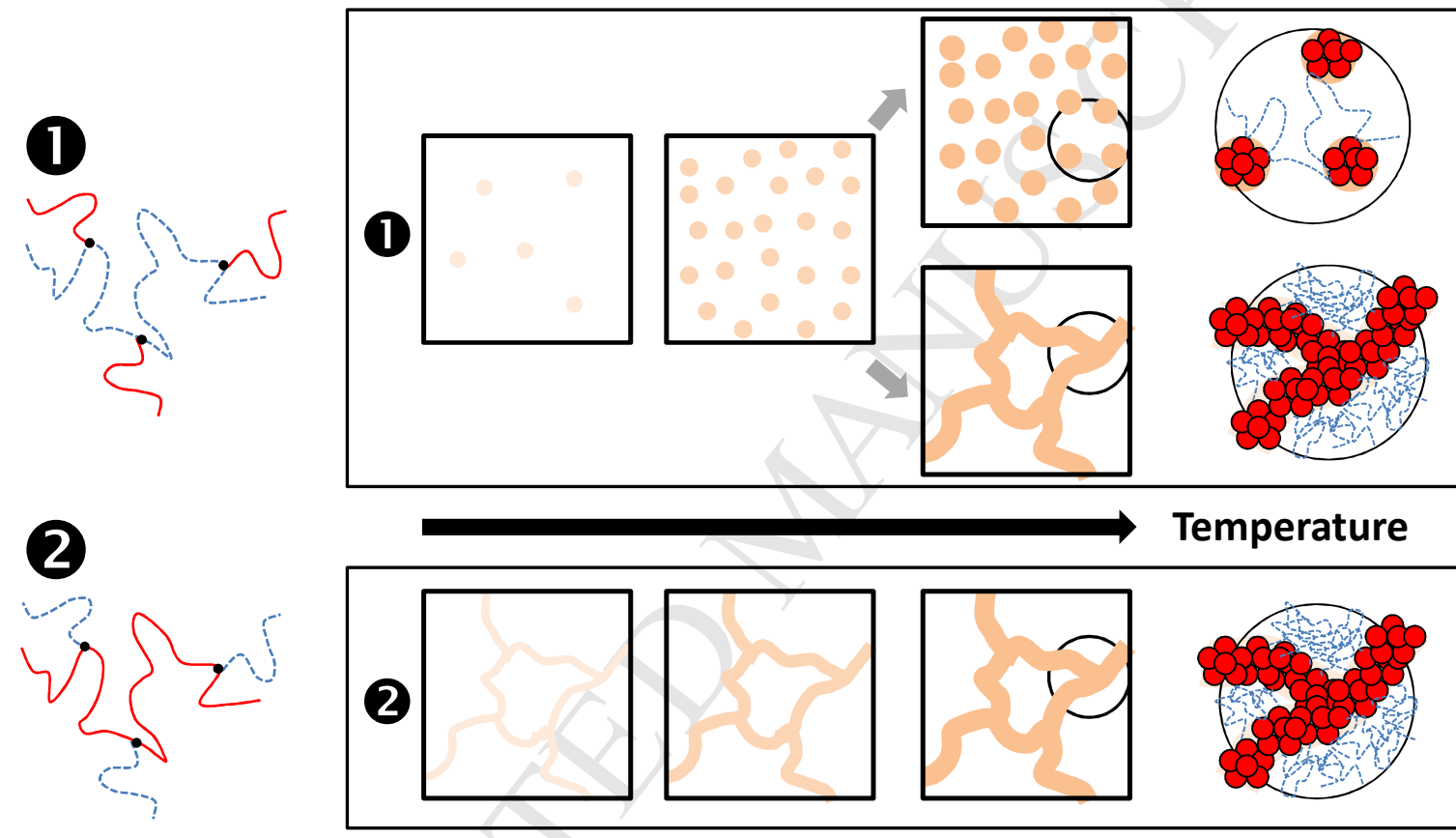

Figure 14. Schematic representation of the thermoassociation behavior of PD-N (0) and PN-D (2) copolymers in aqueous media.

In the first case, the percolation and the viscoelastic properties originate from the PDMA backbones making bridges between PNIPA domains. In the other situation, both PDMA chains and percolating PNIPA aggregates will behave as physical bridges in the macroscopic properties. By comparison, DSC, NMR and SANS data show that PN-D chains undergo an abrupt micro-phase separation above the transition temperature that rapidly leads to the formation of concentrated PNIPA domains with sharp interface. Contrary to the copolymer 
with PNIPA side-chains, the phase transition of the PNIPA backbone is almost achieved between 35 and $40{ }^{\circ} \mathrm{C}$. Above this temperature, the mobility of PNIPA, as seen by NMR, is highly reduced in agreement with the vicinity of the glass transition of the binary PNIPA/water system, and the slight increase of composition observed at higher temperatures can be attributed to a continuous release of water from the aggregates. As PN-D chains are able to form a stable percolating network with elastic properties above $3 \mathrm{wt} \%$, we can reasonably assume that PNIPA sequences of the backbone self-assemble into a bicontinuous two-phase structure. According to the schematic description given in Figure 14, PNIPA sequences inserted between PDMA side-chains collapse above their transition temperature and form sticky globules that self-associate into a percolating 3D structure. This mechanism can be compared to the one reported with aqueous solutions of pure linear PNIPA as they also form physical networks during phase separation above some overlap concentration [52,53]. Nevertheless for pure PNIPA, the non-equilibrium morphologies, which are kinetically controlled, are much less stable with time or under high deformation. This is not the case with graft copolymers, PD-N and PN-D, as PDMA sequences stabilize in water the morphologies above the LCST and the macroscopic properties remain totally reversible by cycling the temperature. The fact that we also consider in Figure 14 the possibility for PD-N chains to form a percolating network of PNIPA aggregates, like PN-D, comes from the strong similarity of their viscoelastic properties in spite of their inverse topologies. On the one hand, this similarity is quite reasonable for the complex viscosity at low temperature as, in the nonassociating state, similar solubility and swelling behaviors are expected for the two copolymers having close average molar masses and composition. As shown in Figure 15, the viscosities are in agreement with theoretical scaling exponents calculated for unentangled $(\mathrm{x}=5 / 4)$ and entangled $(\mathrm{x}=15 / 4)$ semi-dilute solutions of polymer in good solvent [54]; the entangled regime starting around $5 \mathrm{wt} \%$. Quantitatively, the overlap concentration can be 
calculated at $25^{\circ} \mathrm{C}$ from the radius of gyration $\left(\mathrm{R}_{\mathrm{G}}=35 \mathrm{~nm}\right.$ in Table 2$)$ and the molar mass of the copolymers $\left(\mathrm{M}=400000 \mathrm{~g} / \mathrm{mol}\right.$; see Table 1). This gives $\mathrm{C}^{*} \approx 0.4 \mathrm{wt} \%$ for both PN-D and PD-N, in good agreement with experimental data of Figure 9 if we assume that the solution viscosity at $C^{*}$ should be twice the viscosity of the solvent $(\eta \approx 0.002$ Pa.s) [55]. Similarly, if we consider that $\mathrm{C}^{*}$ is about $0.4 \mathrm{wt} \%$ for both copolymer samples, this means that at $5 \mathrm{wt} \%$ each chain overlaps with at least 10 others which is a good criterion for the beginning of the entangled regime according to Dobrynin et al. [56].

While these rheological data are quite expected at room temperature, the results are more surprising at high temperature where similar elastic moduli were obtained for both PN-D and PD-N solutions. This leads us to believe that a similar self-assembly of PN-D and PD-N in water underlies their macroscopic properties.

In this framework, one of the main features of the micro-phase separation of PNIPA sequences is the important slowing down of the polymer dynamics. The "glassy" behavior, or more precisely the low dynamics of PNIPA aggregates, is of prime importance as the lifetime of the associations is responsible for the covalent-like 3D network observed at high temperature. Moreover the abrupt transition of the PN-D sample, together with the formation of concentrated aggregates of low mobility, gives the possibility to freeze the micro-phase separated structure during the early stage of the transition.

In the case of PN-D solution, the concentration is a critical parameter and a stable thermothickening behavior was observed only at a sufficiently high concentrations (3 wt\% and above), mainly in the semi-dilute entangled regime where intermolecular associations overcome the intramolecular collapse of the chains. Below this concentration, the formation of loosely connected or unconnected clusters will only provide poor viscous properties. On the other hand, the PD-N copolymer is more stable at lower concentration (below $3 \mathrm{wt} \%$ ): this 
gives rise to viscosity enhancement through the formation of PDMA bridges between unconnected PNIPA clusters.

It is interesting to notice that when stable gels are formed, either with PN-D or PD-N, they exhibit very similar elastic modulus at the same polymer (or PNIPA) concentration with a quadratic dependence of G' on concentration (see Figure 15).

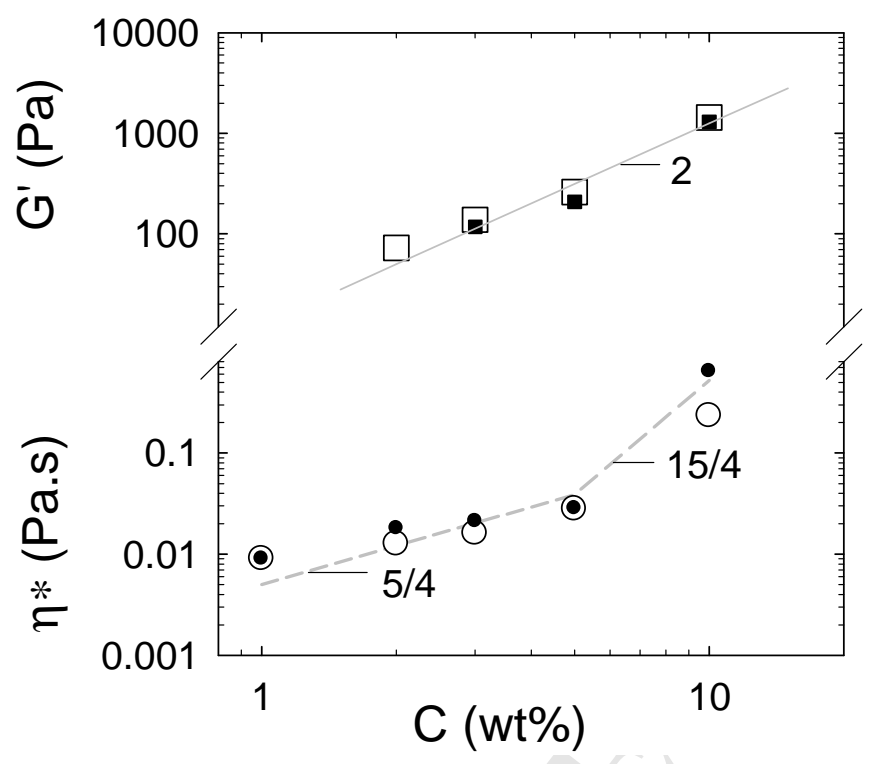

\section{Figure 15}

Concentration dependence of complex viscosity at $20^{\circ} \mathrm{C}(\bigcirc)$ and elastic modulus at $60^{\circ} \mathrm{C}(\square \mathbf{\square})$ for PD-N (hollow symbols) and PN-D (filled symbols) aqueous solutions.

Dotted lines are used as guide lines

Taking into account the picture of a bicontinuous structure, where the mechanical properties are mainly brought by the concentrated PNIPA phase, this mechanical behavior is comparable with open-cell polymer foams where the elastic modulus of the material varies with the modulus of the wall and the square of their volume fraction [57]. Working close to the concentration threshold of the copolymers (3 wt\%), the addition of salt or surfactant reveals real differences with opposite macroscopic behaviors. For the PD-N sample, addition of salt (or SDS) decreases (or increases) the association temperature as expected from the solubility of PNIPA chains. These additives also modify the elastic modulus in the gel state as 1) salt slightly deswells the PDMA backbone, decreasing the degree of overlapping, and 2) SDS 
decreases the number of PNIPA stickers by forming polyelectrolyte necklaces. On the other hand, while the shift of the association temperature is similar for PN-D compared to PD-N, both salt and SDS dramatically ruins the 3D scaffold initially formed in water. In the first situation, the loss of connectivity can be correlated to a lower stabilization of PNIPA domains by PDMA hydrophilic side-chains; the characteristic wavelength of the microphase separation increasing with salt concentration. In the presence of SDS, the opposite effect is observed with the formation of smaller PNIPA aggregates which become more repulsive with the binding of SDS molecules.

\section{ACKNOWLEDGEMENTS}

We gratefully acknowledge the financial support of CNRS, ESPCI and UPMC, the China Scholarship Council for the PhD fellowship funding of Hui Guo and CEFIPRA for promoting Indo-French collaboration. The authors also thank Dr Guylaine Ducouret for technical advice on performing rheological measurements.

\section{REFERENCES}

[1] Polymers in aqueous media: performance through association; J. Edward Glass Ed.; Advances in Chemistry Series 1989;223.

[2] Taylor KC, Nasr-El-Din HA. J Petrol Sci Eng 1998;19:265-280.

[3] Wever DAZ, Picchioni F, Broekhuis AA. Prog Polym Sci 2011;36:1558-1628.

[4] Dimitrov I, Trzebicka B, Müller AHE, Dworak A, Tsvetanov CB. Prog Polym Sci 2007;32:1275-1343.

[5] Schattling P, Jochum FD, Theato P. Polym Chem 2014;5:25-36. 
[6] Barabanova A, Molchanov V, Philippova O, Khokhlov A. Macromol Symp 2014;337:8086.

[7] Liu R, Fraylich M, Saunders, B. R. Colloid Polym Sci 2009,287, 627-643.

[8] L'Alloret F. U.S. Patent US7115255, 2001.

[9] Maroy P, Hourdet D, L’Alloret F, Audebert R. European Patent EP0583814, 1993.

[10] Drury JL, Mooney DJ. Biomaterials 2003;24:4337-4351.

[11] Gutowska A, Jeong B, Jasionowski M. Anat Rec 2001;263:342-349.

[12] Bhattarai N, Ramay HR, Gunn J, Matsen FA, Zhang M. J Controlled Release 2005;103:609-624.

[13] Cohn D, Sosnik A, Garty S. Biomacromolecules 2005;6:1168-1175.

[14] Heymann E. Trans Faraday Soc 1935;31:846-864.

[15] Klug ED. J Polym Sci Part C 1971;36:491-508.

[16] Durand A, Hervé M, Hourdet D. Stimuli-Responsive Water Soluble and Amphiphilic Polymers; McCormick CL, Ed.; ACS SymposiumSeries 780; American Chemical Society: Washington, DC, 2000; Chapter 11:181-207.

[17] Hourdet D, L'Alloret F, Audebert R. Polymer 1994;35:2624-2630.

[18] Hourdet D, L'Alloret F, Durand A, Lafuma F, Audebert R, Cotton J-P. Macromolecules 1998;31:5323-5335.

[19] Bromberg L. Macromolecules 1998;31:6148-6156.

[20] Durand A, Hourdet D. Polymer 1999;40:4941-4951.

[21] Petit L, Karakasyan C, Pantoustier N, Hourdet D. Polymer 2007;48:7098-7112.

[22] Karakasyan C, Lack S, Brunel F, Maingault P, Hourdet D. Biomacromolecules 2008;9:2419-2429.

[23] Siband E, Tran Y, Hourdet D. Macromolecules 2011;44:8185-8194.

[24] Afroze F, Nies E, Berghmans HJ. Mol Struct 2000;554:55-68. 
[25] Aseyev V, Tenhu H, Winnik F. M. Adv Polym Sci 2010;242:29-89.

[26] Philipp M, Müller U, Aleksandrova R, Sanctuary R, Müller-Buschbaum P, Krüger JK. Soft Matter 2012;8:11387-11395.

[27] Balu C, Delsanti M, Guenoun P. Langmuir 2007;23:2404-2407.

[28] László K, Guillermo A, Fluerasu A, Moussaïd A, Geissler E. Langmuir 2010;26:44154420.

[29] Braun O, Boué F, Candau F. Eur Phys J 2002;E7 :141-151.

[30] Gottlieb HE, Kotlyar V, Nudelman A. J Org Chem 1997;62:7512-7515.

[31] Hourdet D, Gadgil J, Podhajecka K, Badiger MV, Brûlet A, Wadgaonkar PP. Macromolecules 2005;38:8512-8521.

[32] Hourdet D, Petit L. Macromol Symp 2010;291-292:144-158.

[33] Schild HG, Tirell DA. J Phys Chem 1990;94:4352-4356.

[34] Otake K, Inomata H, Konno M, Saito S. Macromolecules 1990;23:283-289.

[35] Patel T, Ghosh G, Yusa S-I, Bahadur PJ. Dispersion Sci Technol 2011;32 :1111-1118.

[36] Badiger MV, Rajamohanan PR, Kulkarni MG, Ganapathy S, Mashelkar RA. Macromolecules 1991;24:106-111.

[37] Lele AK, Hirve MM, Badiger MV, Mashelkar RA. Macromolecules 1997;30:157-159.

[38] Durand A, Hourdet D, Lafuma F. J Phys Chem B 2000;104:9371-9377.

[39] Rusu M, Wohlrab S, Kuckling D, Möhwald H, Schönhoff M. Macromolecules 2006;39:7358-7363.

[40] Shibayama M, Tanaka T, Han CC. J Chem Phys 1992;97:6829-6841.

[41] Petit L, Bouteiller L, Brûlet A, Lafuma F, Hourdet D. Langmuir 2007;23:147-158.

[42] Shibayama M, Tanaka T, Han CC. J Chem Phys 1992;97:6842-6854

[43] Auvray L, Cotton J-P, Ober R, Taupin C. J Phys 1984;45:913-928. 
[44] Barnes IS, Hyde ST, Ninham BW, Derian P-J, Drifford M, Zemb T. J Phys Chem 1988;92:2286-2293.

[45] Teubner M, Strey RJ. Chem Phys 1987;87:3195-3200.

[46] L'Alloret F, Hourdet D, Audebert R. Colloid Polym Sci 1995;273:1163-1173.

[47] Lee L-T, Cabane B. Macromolecules 1997;30:6559-6566.

[48] Chen J, Xue H, Yao Y, Yang H, Li A, Xu M, Chen Q, Cheng R. Macromolecules 2012;45:5524-5529.

[49] Borisov OV, Zhulina EB. Macromolecules 2005;38:2506-2514.

[50] Kosovan P, Kuldova J, Limpouchova Z, Prochazka K, Zhulina EB, Borisov OV. Macromolecules 2009;42:6748-6760.

[51] Borisov OV, Halperin A. Current Opinion In Colloid and Interface Science 1998;3:415421.

[52] Yang Y, Zeng F, Tong Z, Liu X, Wu S. J Polym Sci, Part B, Polym Phys 2001;39:901907.

[53] Kressler J, Kammer H-W. Self-Healing Polymers : From Principles to Applications, Binder WH Ed.; Wiley-VCH Verlag GmbH: Weinheim, 2013; Chap 5:139-152.

[54] Rubinstein M, Semnov AN. Macromolecules 1998;31:1386-1397.

[55] Colby RH. Rheol Acta 2010;49:425-442

[56] Dobrynin AV, Colby RH, Rubinstein M. Macromolecules 1996;28:1859-1871.

[57] Ashby MF. Metall Mater Trans A 1983;14:1755-1769. 


\section{Highlights}

- Two LCST-based graft copolymers with reverse topologies were prepared from PNIPA and PDMA.

- Aqueous solution properties were studied by DSC, NMR, neutron scattering and rheology.

- The two copolymers undergo similar sol/gel transition upon heating in the entangled regime.

- Transition is more abrupt when PNIPA is used as backbone (PN-D) instead of grafts (PD$\mathrm{N})$.

- When unentangled, PN-D chains do not percolate in the presence of salt or surfactants. 


\section{Supporting Information}

Influence of topology of LCST-based graft copolymers on responsive assembling in aqueous media.

Hui Guo ${ }^{1,2}$, Annie Brûlet ${ }^{3}$, Pattuparambil R. Rajamohanan ${ }^{4}$, Alba Marcellan ${ }^{1,2}$, Nicolas Sanson $^{1,2}$ and Dominique Hourdet ${ }^{1,2 *}$

${ }^{1}$ École Supérieure de Physique et de Chimie Industrielles de la Ville de Paris (ESPCI), ParisTech, PSL Research University, Sciences et Ingénierie de la Matière Molle, CNRS UMR 7615, 10 rue Vauquelin, F-75231, Paris cedex 05, France.

${ }^{2}$ Sorbonne-Universités, UPMC Univ Paris 06, SIMM, 10 rue Vauquelin, F-75231 Paris cedex 05, France.

${ }^{3}$ Laboratoire Léon Brillouin (CNRS UMR 12), CEA Saclay, F-91191 Gif-sur-Yvette Cedex, France

${ }^{4}$ Central NMR Facility, CSIR-National Chemical Laboratory, Pune 411 008, India

\section{Synthesis of thermosensitive linear copolymers}

The synthesis of responsive linear copolymers was performed according to a three-step process that is summarized as follows.

\section{1) Synthesis of Amino-Terminated Telomers}

The synthesis of functional chains was achieved by radical polymerization using an efficient chain transfer agent AET. This telomerization allows controlling the end group of the polymer as well as its molar mass. In a three necked flask, $100 \mathrm{mmol}$ of monomers (NIPA or DMA) 
was dissolved in $100 \mathrm{~mL}$ of water and the solution was deoxygenated for $1 \mathrm{~h}$ with nitrogen bubbling. The redox initiators, KPS $(1.0 \mathrm{mmol})$ and AET $\cdot \mathrm{HCl}(2.0 \mathrm{mmol})$, were separately dissolved in $10 \mathrm{~mL}$ of water and deoxygenated for $30 \mathrm{~min}$ before adding to the monomer solution. The reaction was allowed to proceed in an ice bath, in order to avoid the phase separation of the reaction medium in the case of PNIPA. SEC was applied to monitor the polymerization process. After $4 \mathrm{~h}$, no monomer was left according to SEC, and an appropriate amount of sodium hydroxide was added to neutralize the hydrochloride ions and the polymer was recovered by dialysis against pure water (membrane cut-off $=3.5 \mathrm{kDa}$ ) for one week and freeze-dried. The telomers were obtained with a yield of $70 \mathrm{wt} \%$.

\section{2) Synthesis of linear macromonomers}

Typically for the PNIPA macromonomer, $6.0 \mathrm{~g}$ of amino-terminated telomers (about 0.26 mmol) and $0.29 \mathrm{~g}$ of AA (4 mmol) were initially dissolved in $50 \mathrm{~mL}$ of NMP at room temperature. After dissolution, $0.8 \mathrm{~g}$ of DCCI $(4 \mathrm{mmol})$, initially dissolved in a minimum of NMP, was introduced rapidly and the reaction was allowed to proceed overnight under stirring at room temperature. After dilution with $100 \mathrm{~mL}$ of water, the polymer was purified by dialysis against pure water (membrane cut-off=3.5 kDa) for one week, and the aqueous solutions were filtered and freeze dried. The reaction was almost quantitative and the PNIPA macromonomer was obtained with a yield of $95 \mathrm{wt} \%$. A similar process was applied for PDMA macromonomers, with a yield of $95 \%$.

\section{3) Synthesis of graft copolymers}

The reaction was carried out in aqueous solution in a three necked flask immersed in an ice bath. Typically, for the synthesis of PDMA- $g$-PNIPA, $5 \mathrm{~g}$ of PNIPA macromonomer $(0.22$ mmol), $5 \mathrm{~g}$ of DMA $(51 \mathrm{mmol})$ and $3.4 \mathrm{mg}$ of SBS $(0.018 \mathrm{mmol})$ were dissolved at low temperature in $100 \mathrm{~mL}$ of water and let for $1 \mathrm{~h}$ under nitrogen atmosphere. Then, ammonium 
peroxodisulfate $(14.4 \mathrm{mg}, 0.063 \mathrm{mmol})$ was dissolved in a small amount of water, deoxygenated, and transferred under nitrogen atmosphere into the reaction medium. The reaction was allowed to proceed below $10{ }^{\circ} \mathrm{C}$ and the conversion with time of both monomer and macromonomer was controlled by SEC. At the end of the reaction, the copolymer solution was purified by dialysis directly against pure water (membrane cut-off $=50 \mathrm{kDa}$ ) for three weeks and freeze-dried. The PDMA-g-PNIPA was obtained with a yield of $88 \mathrm{wt} \%$. A similar process was applied for PNIPA- $g$-PDMA, with a yield of $90 \%$.

\section{Viscoelastic analysis}

As shown in Figure S1, the complex viscosity $\left(\eta^{*}\right)$ can be used to describe the thermothickening behavior of graft copolymer solutions as this single parameter is proportional to the loss modulus in the liquid state (low temperature) and to the storage modulus in the gel state (at high temperature).

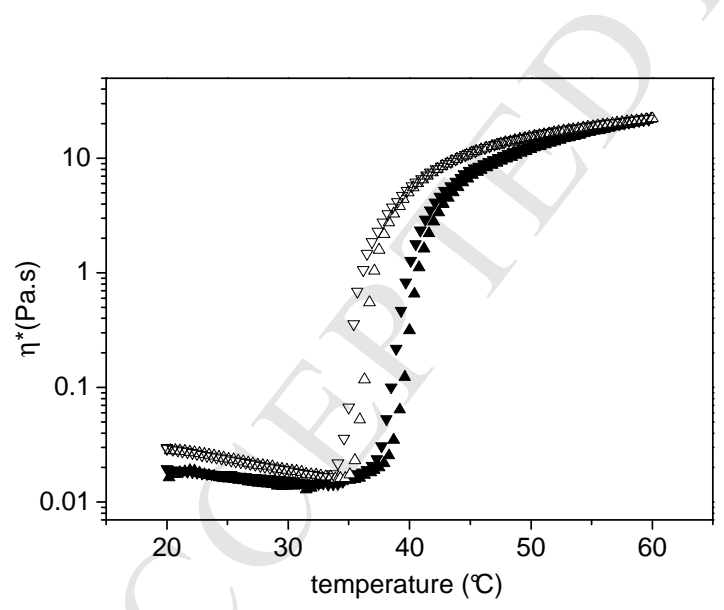

\section{Figure S1}

Temperature dependence of complex viscosity of PD-N ( $\mathbf{\Delta} \boldsymbol{\nabla})$ and $\mathrm{PN}-\mathrm{D}(\triangle \nabla)$ aqueous solutions under heating (regular triangles) or cooling (inverted triangles) $(\mathrm{Cp}=3 \mathrm{wt} \%, \mathrm{f}=1 \mathrm{~Hz}$, heating or cooling rate $=2{ }^{\circ} \mathrm{C} / \mathrm{min}$ ).

At high temperature, well above the transition threshold, the copolymers solutions behave like elastic gels with a high elastic modulus (compared to the viscous modulus) that is almost independent of the frequency (Figure S2). 


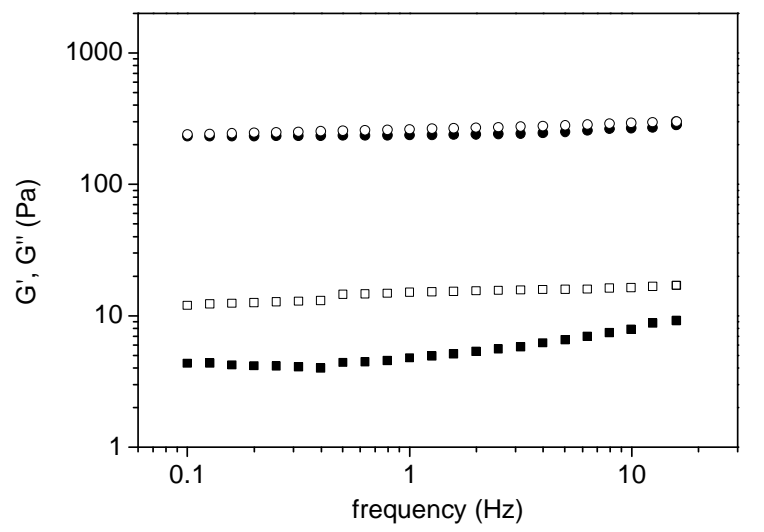

Figure S2

Frequency dependence of elastic $(\bigcirc)$ and loss $(\square \square)$ moduli of 3 wt $\%$ aqueous solutions of PD-N (full) and PN-D (hollow) at $60^{\circ} \mathrm{C}$.

As shown in supporting information (Figure S3), there is no significant modification of the thermodynamic behavior of PNIPA replacing $\mathrm{H}_{2} \mathrm{O}$ with $\mathrm{D}_{2} \mathrm{O}$; or at least the difference remains within $1{ }^{\circ} \mathrm{C}$ as already reported in the literature.

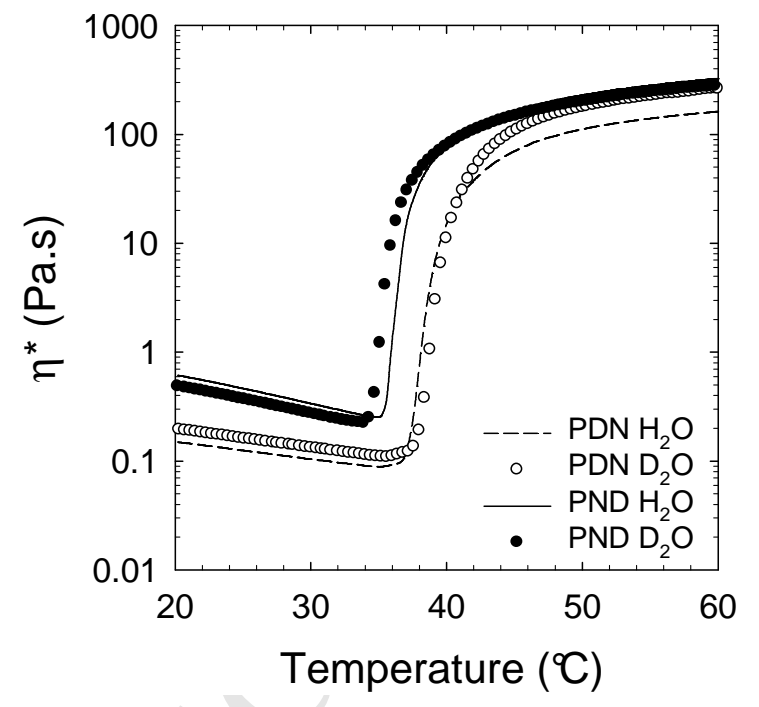

Figure S3

Temperature dependence of complex viscosity $\left(\eta^{*}\right)$ of PD-N and $\mathrm{PN}-\mathrm{D}$ aqueous solutions

$(\mathrm{Cp}=8 \mathrm{wt} \%, \mathrm{f}=1 \mathrm{~Hz}$, heating rate $=2{ }^{\circ} \mathrm{C} \cdot \mathrm{min}^{-1}$ ) in $\mathrm{H}_{2} \mathrm{O}$ and $\mathrm{D}_{2} \mathrm{O}$.

In the case of incompressible biphasic systems, the invariant is a constant that only depends on volume fraction $\left(\phi_{i}\right)$ and contrast $\left(\rho_{i}\right)$ between the two phases: $Q_{\exp }=Q_{t h}=2 \pi^{2}\left(\rho_{1}-\rho_{2}\right)^{2} \phi_{1} \phi_{2}$. From scattering data analyses performed with PD-N and PND solutions above their transition temperature, it is possible to determine the invariant 
experimentally as shown in Figure S4a. Although the extrapolation of $Q_{\exp }=\int_{0}^{\infty} q^{2} I(q) d q$ is performed within a limited q-range $\left(q<0.05 \AA^{-1}\right)$, the relative error on the experimental value can be considered lower than $10 \%$.

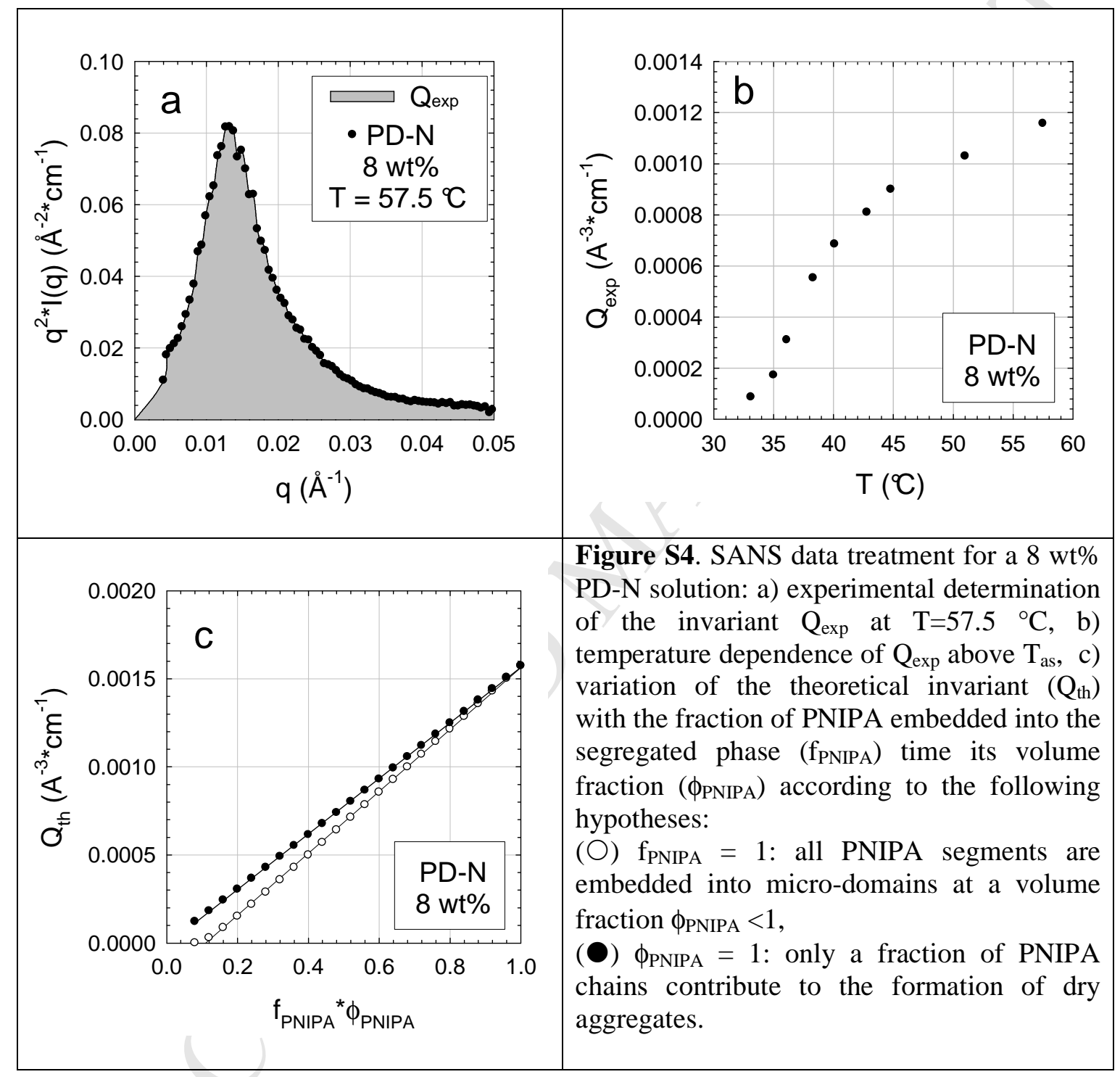

The determination of $\mathrm{Q}_{\exp }$ as a function of temperature (see Figure $\mathbf{S 4 b}$ ) can be used to determine the fraction of PNIPA embedded in the segregated phase $\left(f_{\mathrm{PNIPA}}\right)$ time their volume fraction $\left(\phi_{\mathrm{PNIPA}}\right)$ according to two different hypotheses: 
1) all PNIPA segments are embedded into micro-domains $\left(f_{\mathrm{PNIPA}}=1\right)$ at a volume fraction $\phi_{\mathrm{PNIPA}}<1$; considering the presence of water inside the aggregates,

2) only a fraction of PNIPA chains $\left(f_{\mathrm{PNIPA}}<1\right)$ contribute to the formation of dry aggregates $\left(\phi_{\mathrm{PNIPA}}=1\right)$.

The theoretical plot given in Figure S4c, shows how to calculate the so-called "level of phase separation" $\left(\mathrm{f}_{\mathrm{PNIPA}} * \phi_{\mathrm{PNIPA}}\right)$ from the invariant $\left(Q_{\text {exp }}=Q_{t h}\right)$ according to the different hypotheses. As previously discussed, a relative accuracy of about $10 \%$ can be considered on the extrapolated data.

As shown in Figure S5, the transition enthalpy of graft copolymers PN-D and PD-N does not really depend from the copolymer concentration.
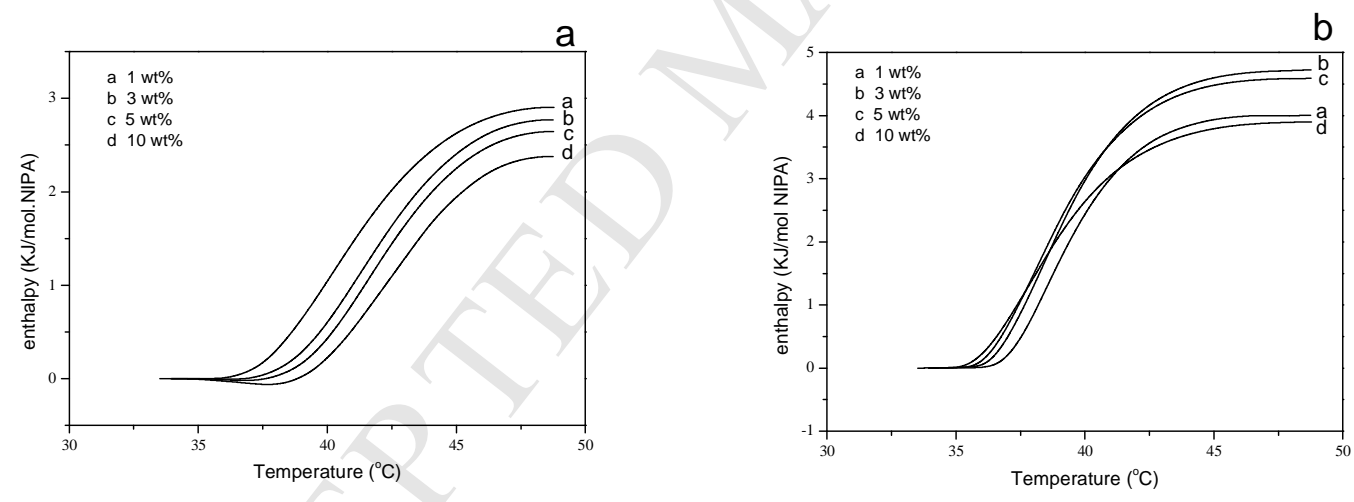

Figure S5. Concentration dependence of the LCST-type phase transition for the two copolymers PD-N (a) and PN-D (b) in aqueous solution. $\left(\mathrm{C}_{\mathrm{p}}\right.$ from 1 to $10 \mathrm{wt} \%$, heating rate $\left.=2^{\circ} \cdot \mathrm{min}^{-1}\right)$.

In the process of the microphase separation of copolymer solutions, the characteristic size of concentration fluctuations may be calculated using the Bragg law $d=2 \pi / q_{\max }$ where $q_{\max }$ is the position of the maximum in the Lorentz-corrected scattering intensity, i.e. $q^{2} I(q)$ vs $q$. As the position of $q_{\max }$ cannot be accurately defined at low concentration (here $3 \mathrm{wt} \%$ ) from the 
original curve $\mathrm{I}(q)$ vs $q$, the Lorentz-corrected intensity has been used in Figure S6 to highlight the variation of this characteristic wavelength at high temperature in the presence of additives.
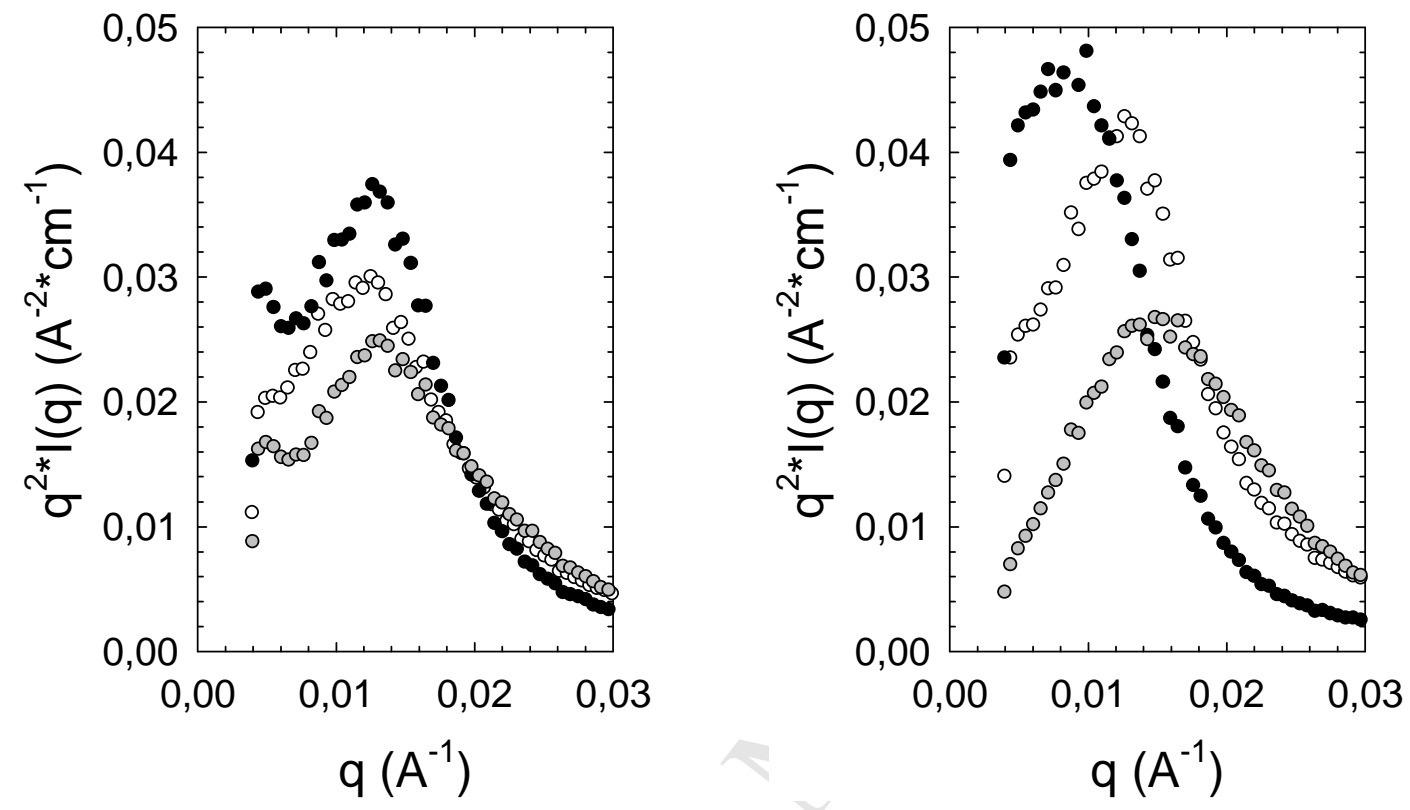

Figure S6. SANS patterns of PD-N (left) and PN-D (right) copolymers at 3 wt \% in water (○), $\mathrm{K}_{2} \mathrm{CO}_{3} 0.3 \mathrm{M}()^{\circ}$ and SDS $2.5 \mathrm{mM}(\odot)$.

All the experiments have been performed at high temperature : $\mathrm{T}=57^{\circ} \mathrm{C}$.

Working well above the percolation threshold, both PD-N and PN-D solutions exhibit similar thermothickening behaviors with sharp sol/gel transitions in the presence of salt (see Figure S7). 

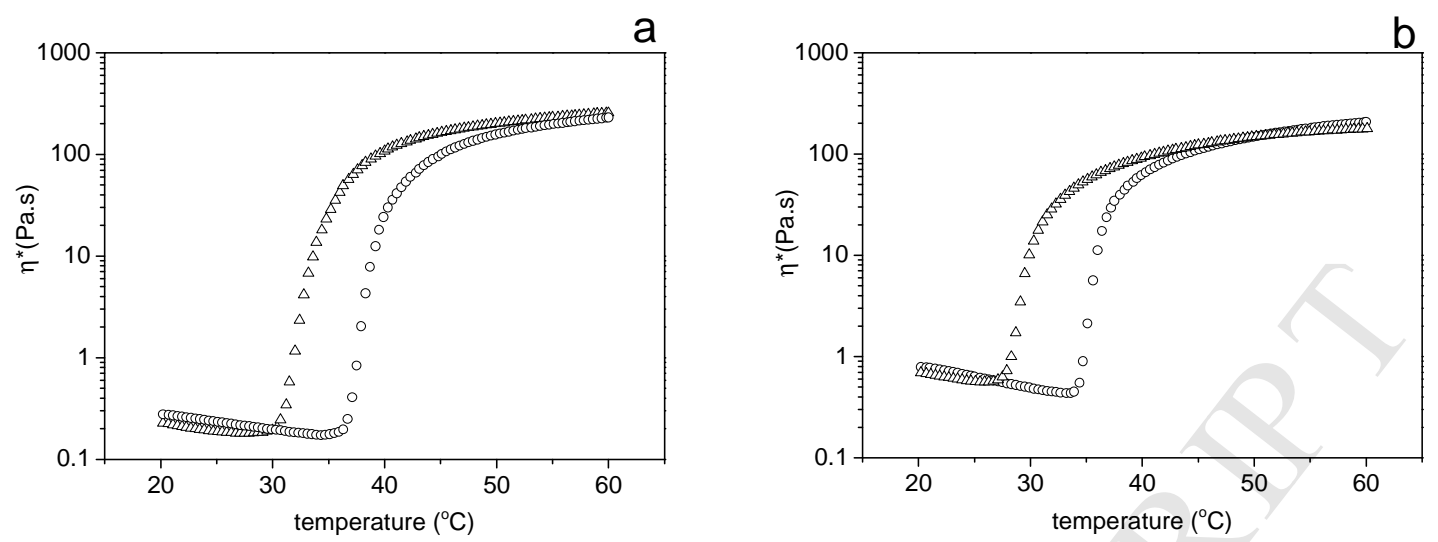

Figure S7. Influence of salt on viscoelastic properties of PD-N (a) and PN-D (b) aqueous solutions $\left(\mathrm{Cp}=10 \mathrm{wt} \%, \mathrm{f}=1 \mathrm{~Hz}\right.$, heating rate $\left.=2{ }^{\circ} \mathrm{C} \cdot \mathrm{min}^{-1}\right)$;

$\left[\mathrm{K}_{2} \mathrm{CO}_{3}\right]=0 \mathrm{~mol} / \mathrm{L}(\mathrm{O})$ and $0.3 \mathrm{~mol} / \mathrm{L}(\triangle)$

As shown by ${ }^{1} \mathrm{H}$ NMR, the binding of SDS molecules on PNIPA sequences will modify the phase separation of PNIPA above their transition temperature by increasing the water content as well as their mobility inside the aggregates (see Figure S8).
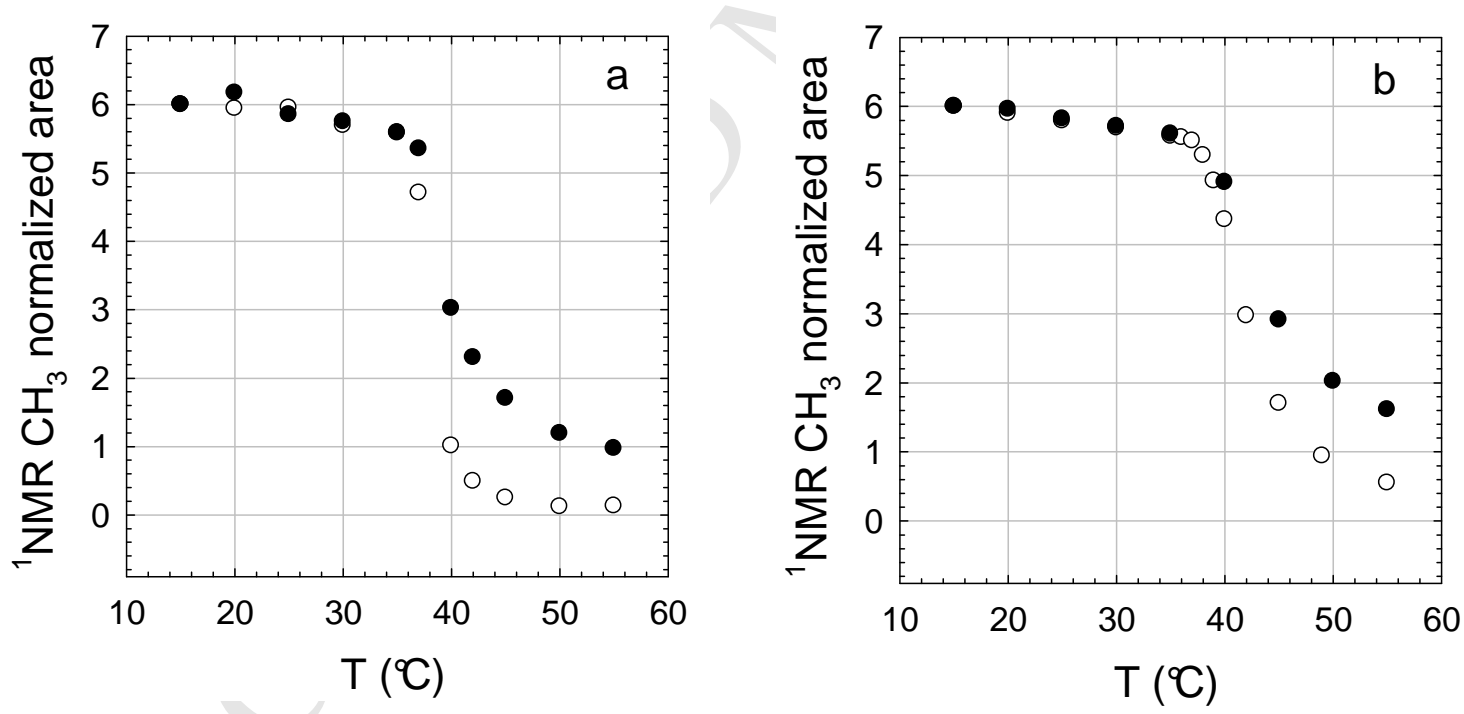

Figure S8. Normalized area of $\mathrm{CH}_{3}$ signal from NIPA units without $(O)$ and with $2.5 \mathrm{mM}$ of $\operatorname{SDS}(\mathbf{O})$ in PN-D (a) and PD-N (b) aqueous solutions $\left(\mathrm{C}=3 \mathrm{wt} \%, \mathrm{D}_{2} \mathrm{O}\right)$. 